\title{
التحكيم في منازعات تتفيذ الصفقات العمومية الدولية في القانون الجزائري
}

Arbitration of Disputes Arising from the Implementation of International Public Procurements in the Algerian Law

تاريخ الاستلام : 2020/05/16 ؛ تاريخ القبول : 2020/08/09

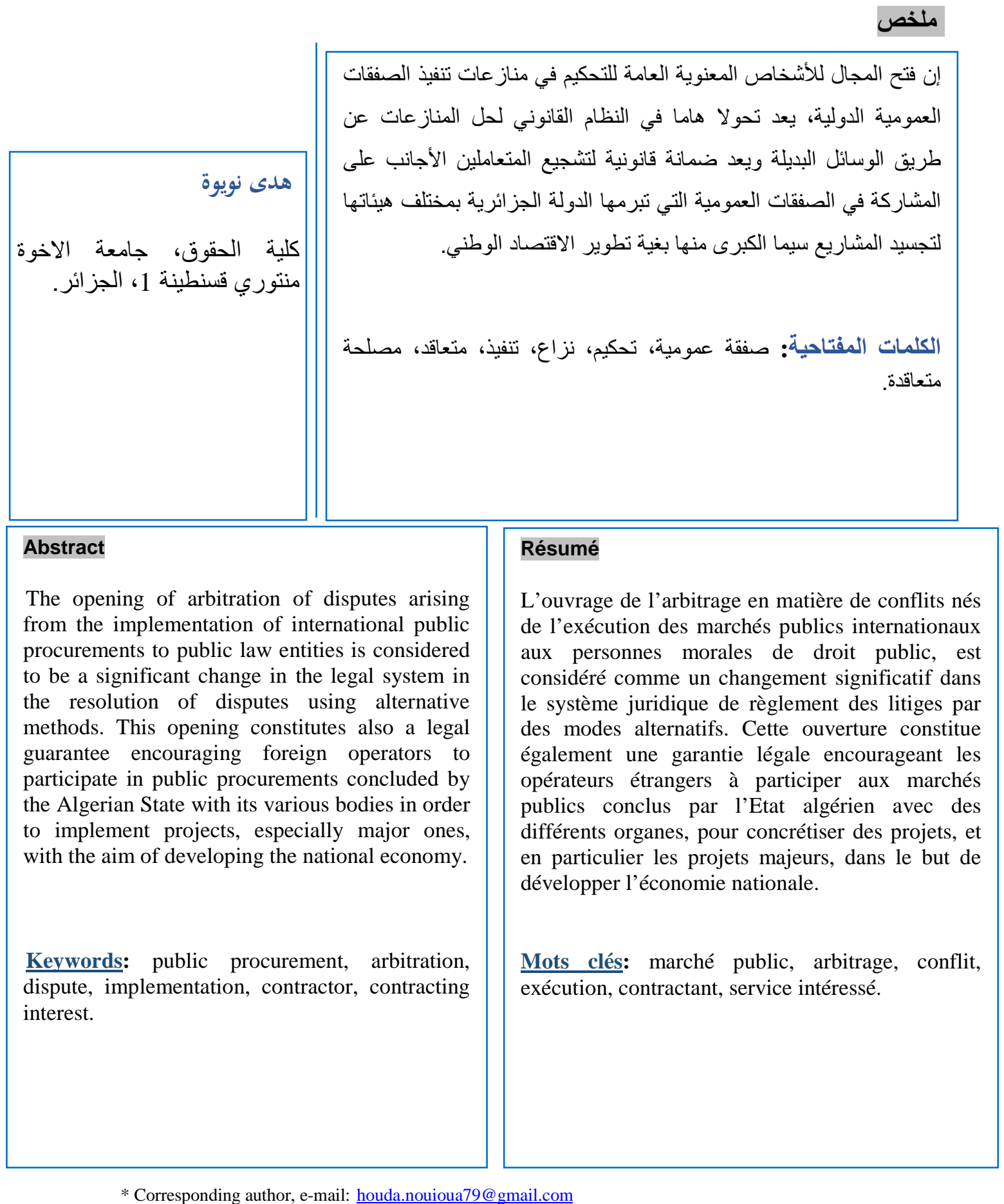

(C) جامعة الاخوة منتوري قسنطينة 1، الجز ائر 2020. 
تعد الصفقات العمومية سواء كانت دولية أو محلية عقودا إدارية لها نظام خاص الاص

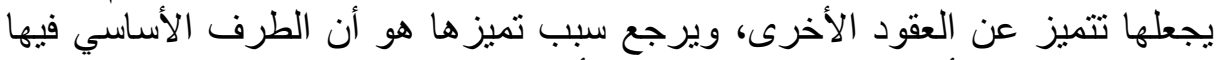

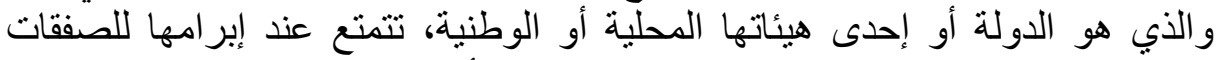

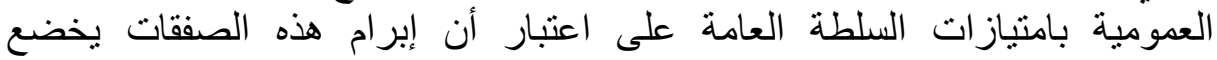

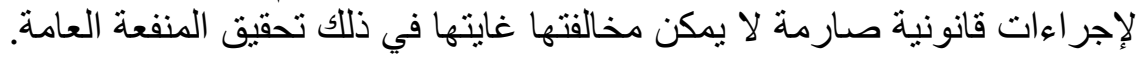

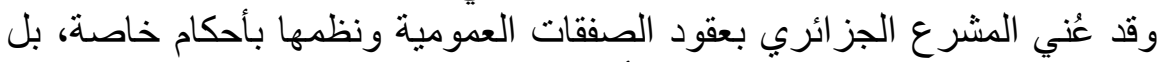

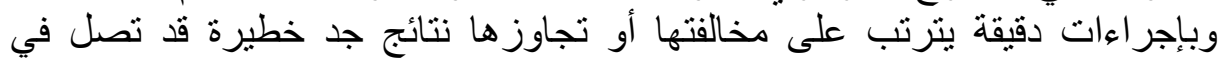

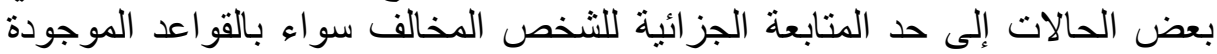

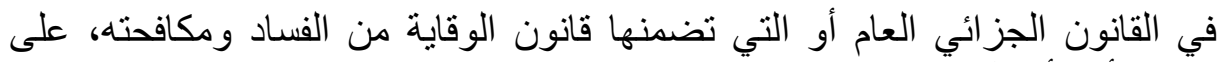

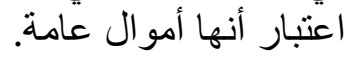

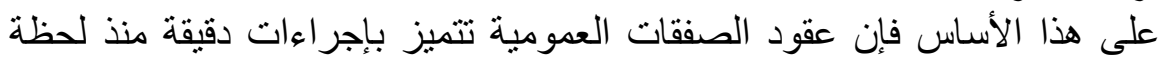

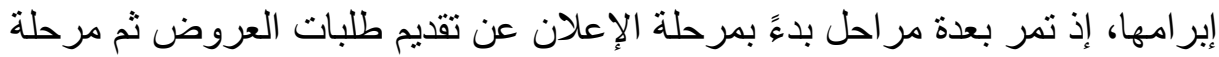

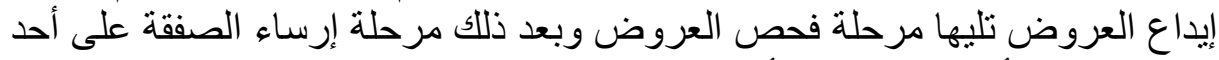

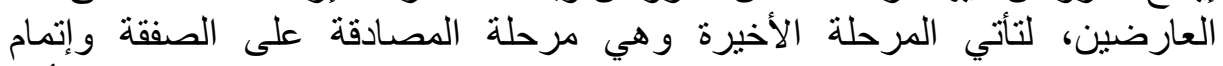

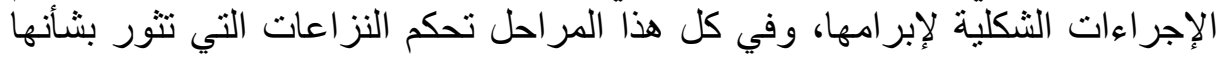

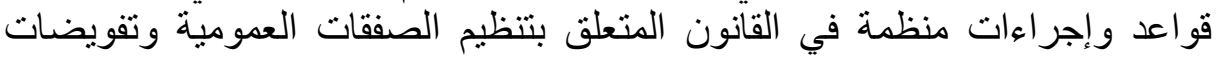

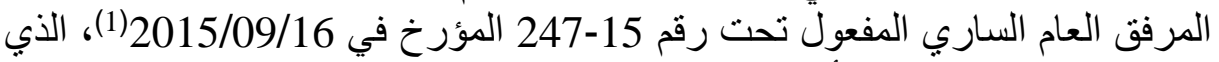

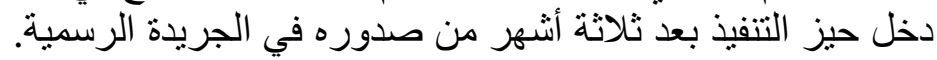

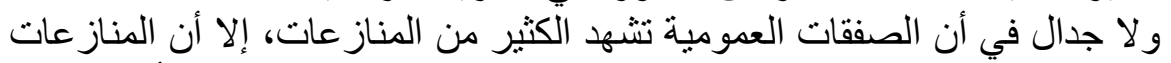

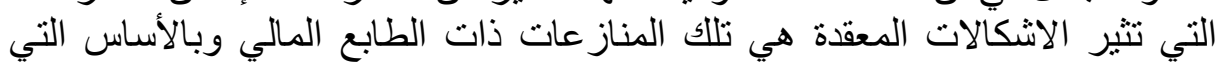

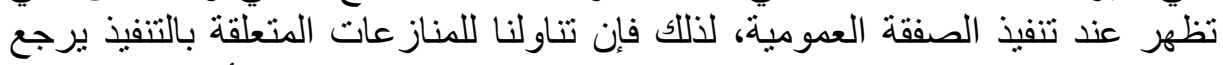

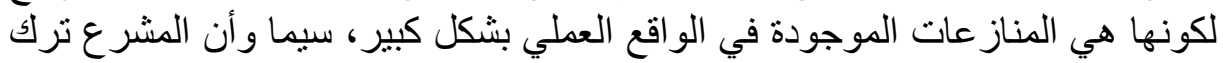

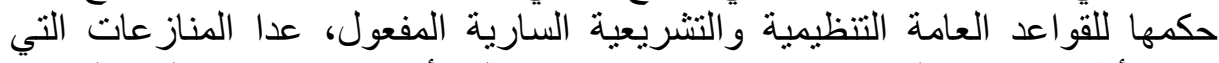

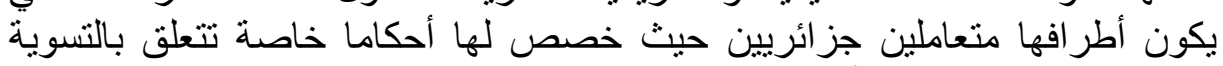

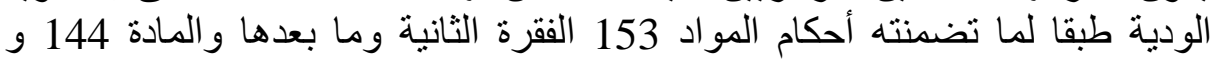
145 من القانون.

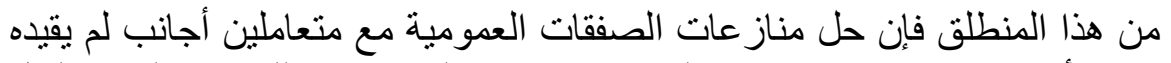

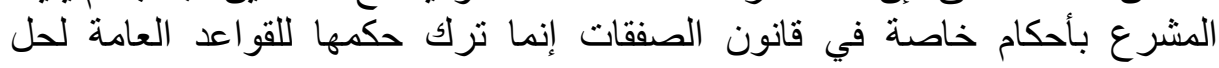

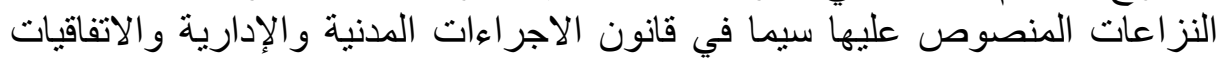
الدولية.

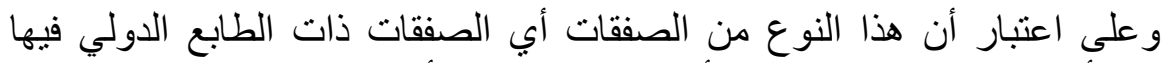

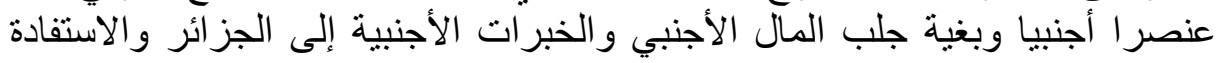

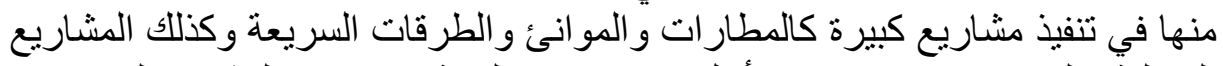

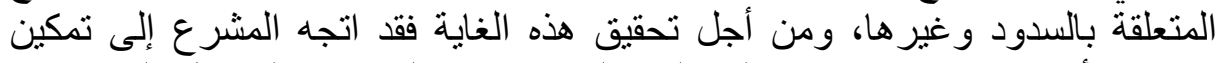

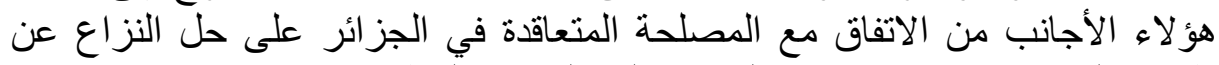

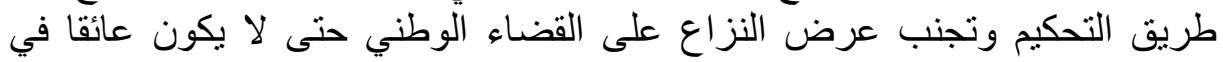
سبيل تتفيذ هذه المشاريع.

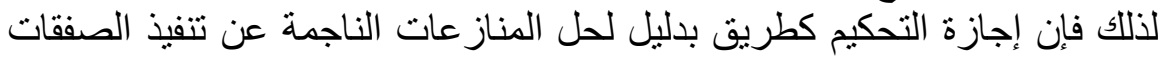

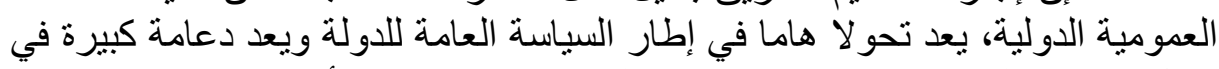

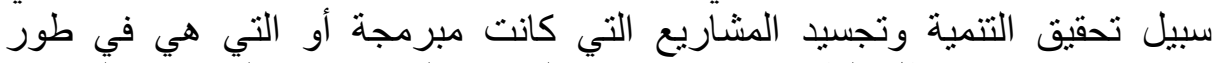
الانجاز خاصة في ظل الظروف الاقتصادية الصعبة التي تعرفها البلاد في التي التينوات 
الأخيرة والانهيار الكبير لأسعار المحروقات وتأثيره على مداخيل الدولة من العملة

على هذا الأساس تتبلور إنكالية البحث في: إلى أبي مدى يمكن اعتبار التحكيم

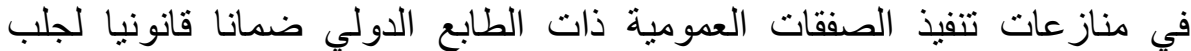

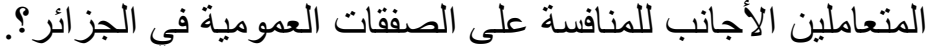

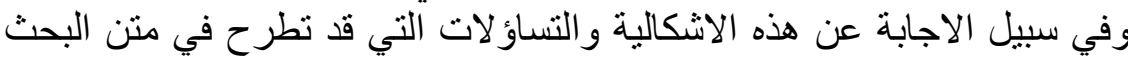

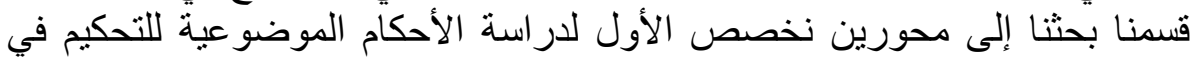

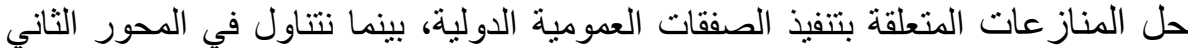

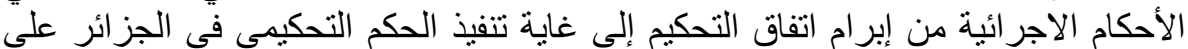
أن نختم بحثنا بنتائج نحسبها ضروام الفاف التهية ومهمة.

\section{الأول: الأحكام الموضوعية للتحكيم في منازعات تنفيذ الصفقات العمومية} الاولية

رغم ما يتميز به التحكيم من أهمية باعتباره وسيلة ودية لتسوية منازعات التهات

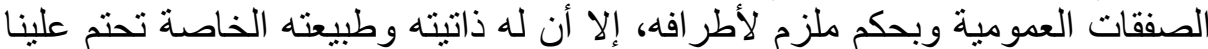
تعريفه بداية وتبيان نطاق تطبيقه فضلا عن صوره و وأشكاله.

\section{أولا: التعريف بالتحكيم في مجال الصفقات العمومية ذات الطابع الدولي}

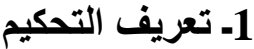

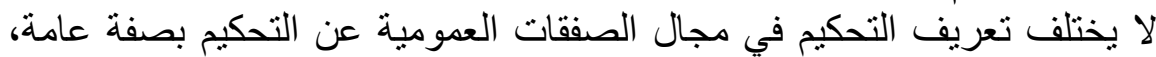

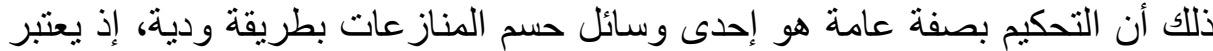

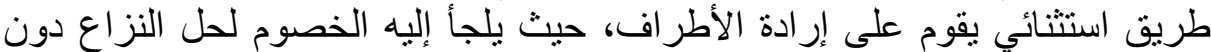
الحاجة لعرضه على القضاء المخلى المختص.

و على ذللك عرفه البعض بأنه" عبارة عن تقنية تهدف إلى إعطاء حل لمسألة تتعلق إنق

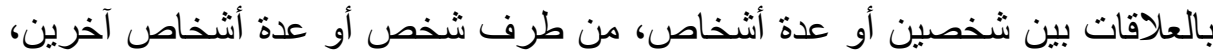

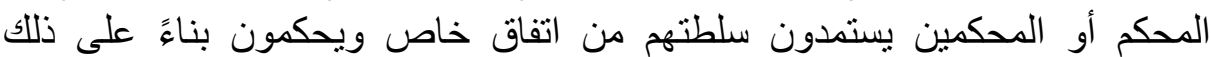

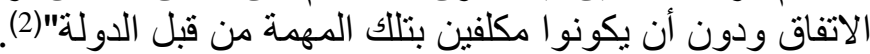

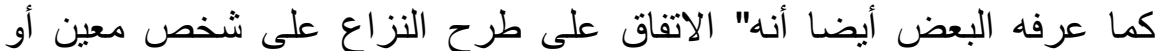

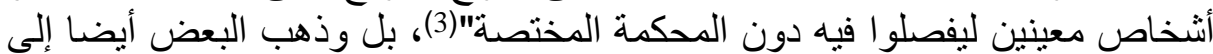

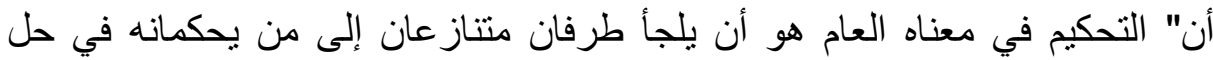

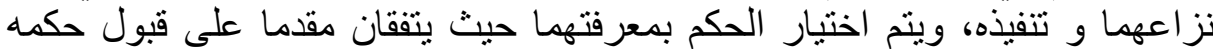

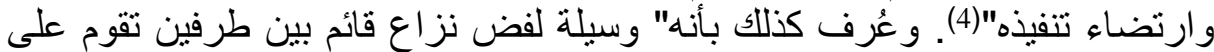

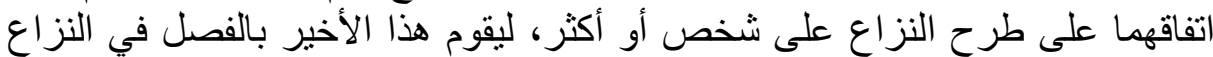

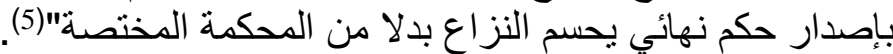

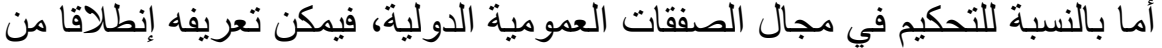

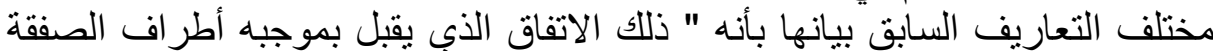

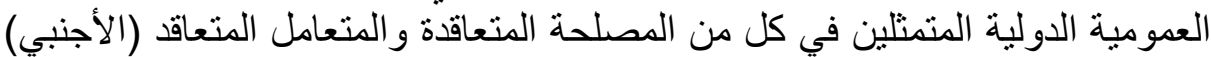

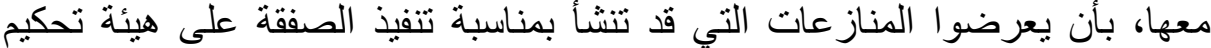
دولية، على أن يخضع هذا الاتفاق لموافقة مسبقة أثناء اجتماع الحكومة وذلتك بناءة

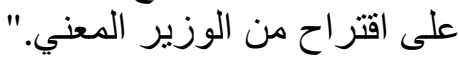

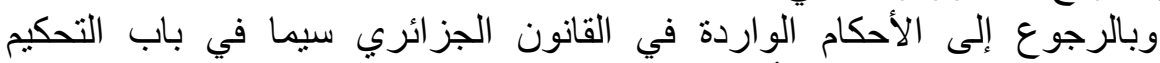
التجاري الدولي على اعتبار أن منازعات التهات تنفيذ الصفقات العمومية الدولية تحكمها لإنيا

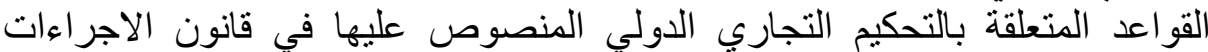

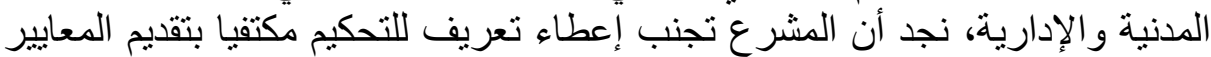




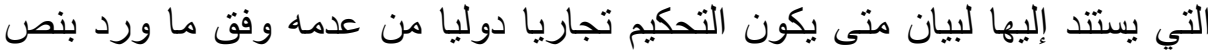

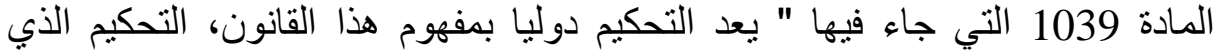

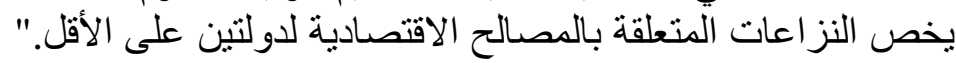

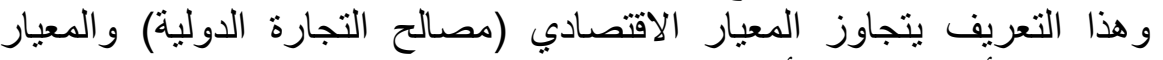
القانوني (تعدد أماكن الإقامة أو تعدد الجنسيات) إلى معيار فيه معيار القتصادي يتعلق

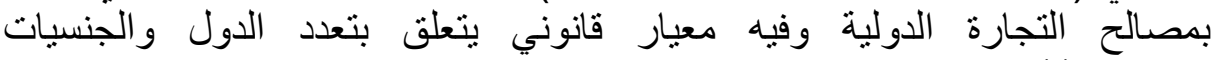

2 - سمات ومزايا التحكيم

للتحكيم عدة خصائص ورئ وزايا جعلته يعرف التنشار ا واسعا على المستوى الدولي

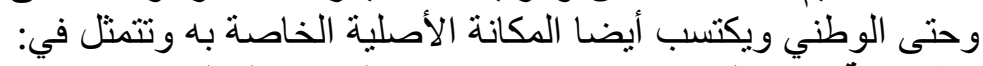

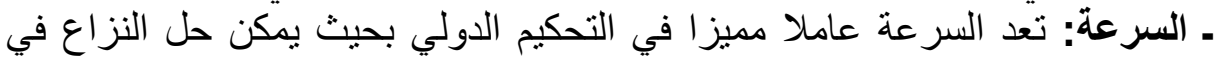

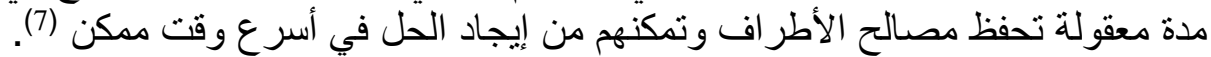

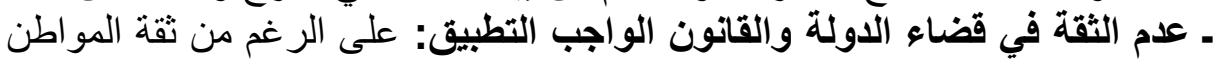

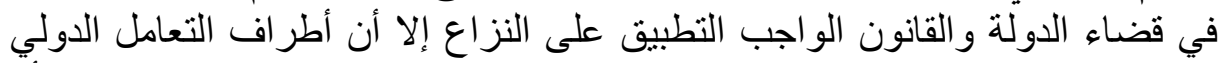

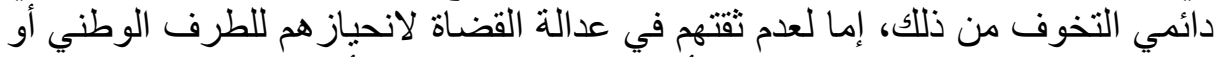

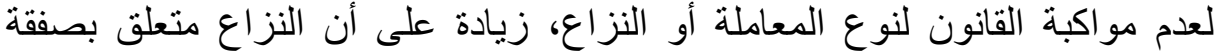

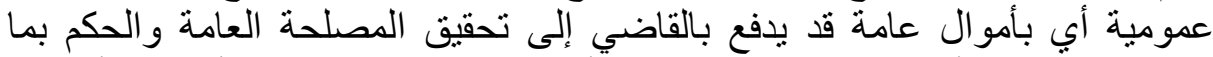

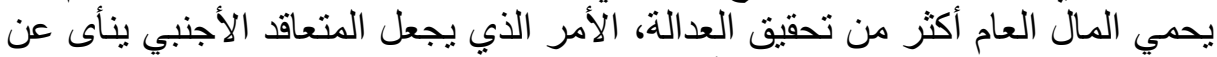

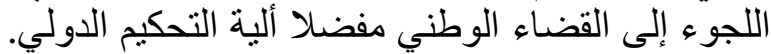

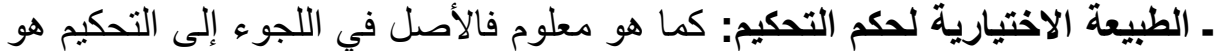

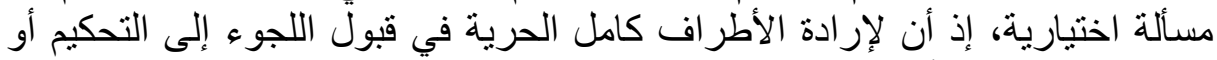

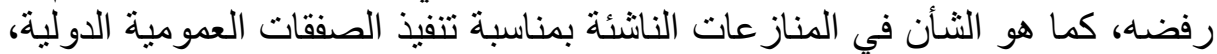

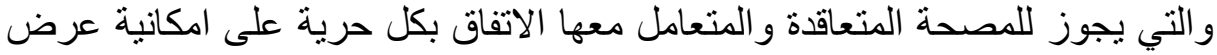

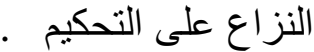
ـ السرية: يفضل أطراف الفناز الفاز عات الحفاظ على سرية المعاملات بينهما وبالتالي

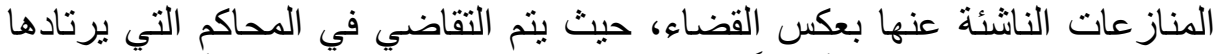
عدد كبير من المتقاضين وأحياناً غير المتقاضين ما قد يضر بمصالح أطر اف الفي النزاع

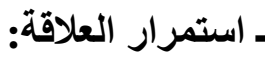
يُفضل أطر اف العلاقة التعاقدية اللجوء إلى التى الوسائل التي تحل منازعاتهم بطريقة

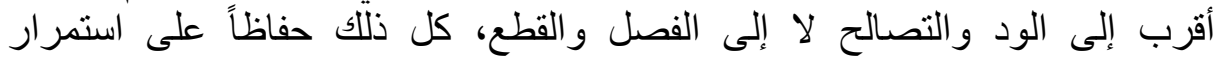

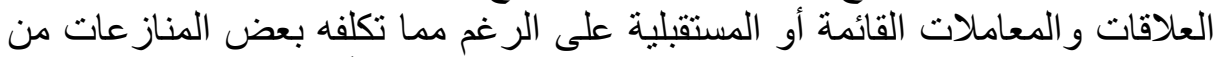

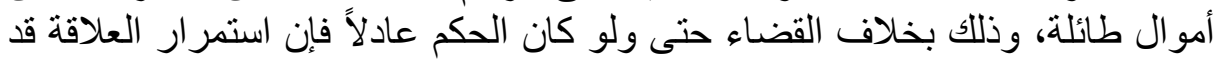
يكون من المستحيل تحقيقه.

ثانيا: نطاق التحكيم في منازعات تنفيذ الصفقات العمومية الاولية

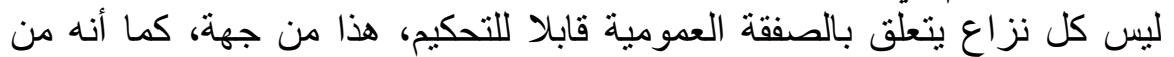

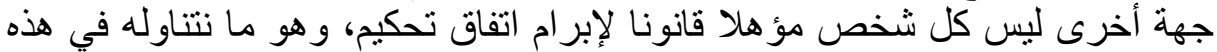

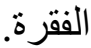

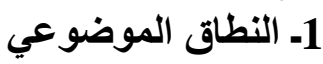
جاء نص المادة 1006 من قانون المونو الإجراءات المدنية والإدارية بفقرتها الأولى

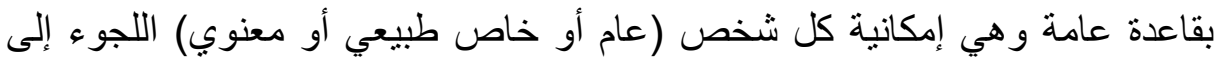


التحكيم، ويكون ذلك بصفة حصرية في الحقوق (الحقوق المالية) التي يكون له مطلق التصرف فيها عدا ما تعلق بالنظام العام وحالات وأهلية أهلية الأشخاص. التهاص.

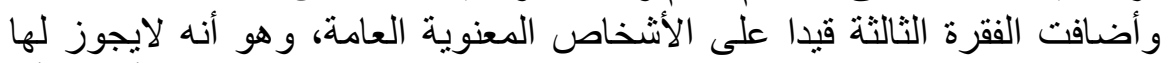

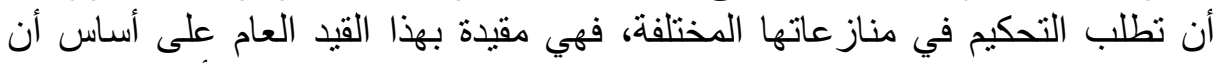

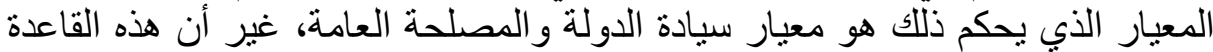

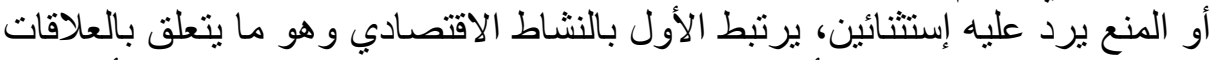

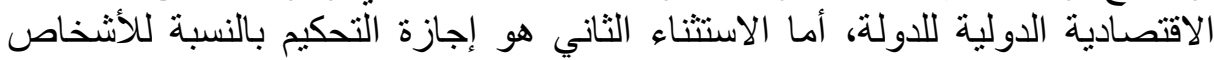

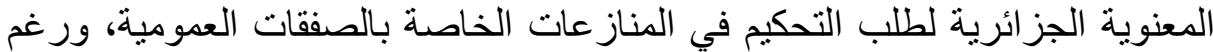

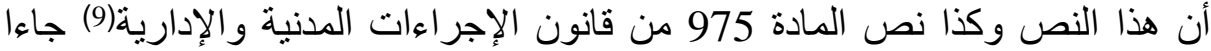

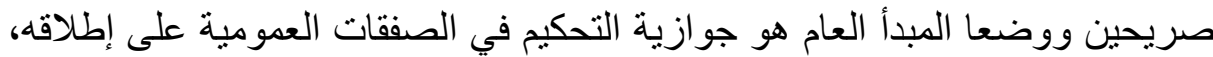

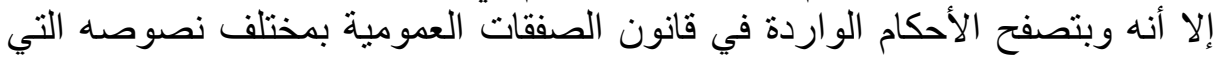

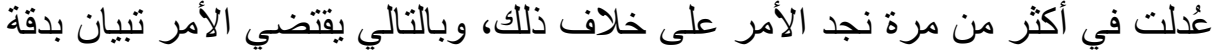

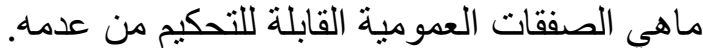

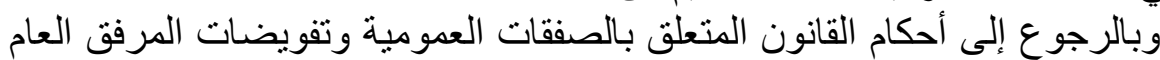

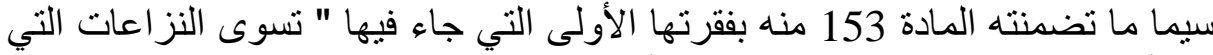

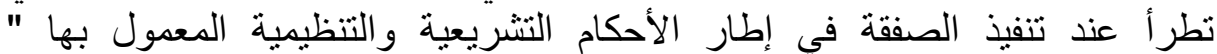

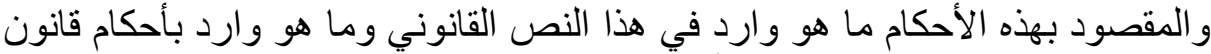

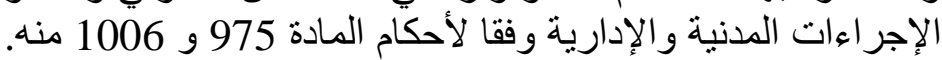

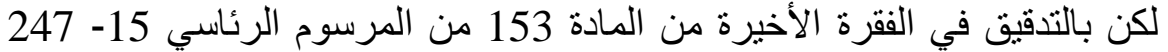

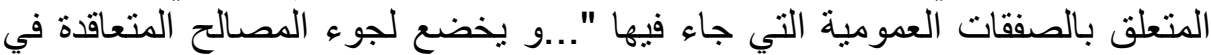

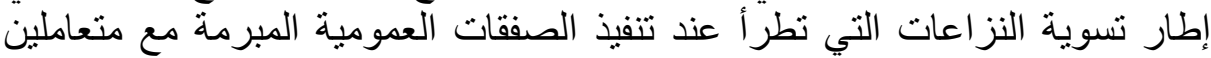

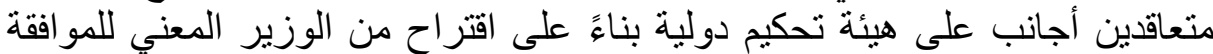

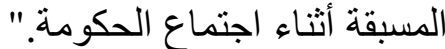

إذا ما نستشفه من هذه النصوص أنساء أن منازعات الصفقات العمومية التي يجوز فيها

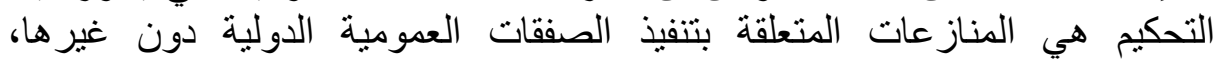

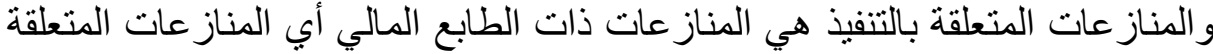

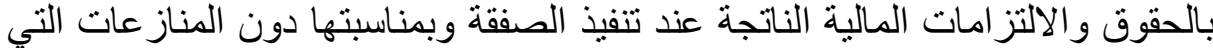

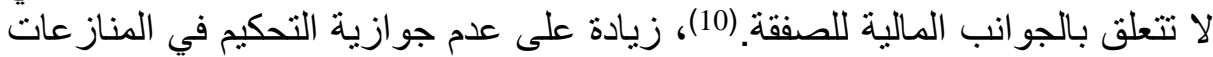

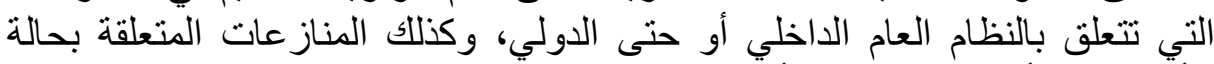

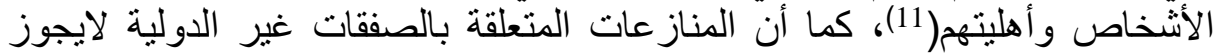

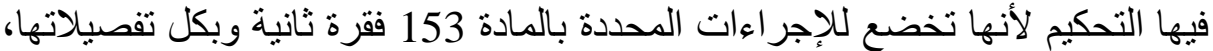

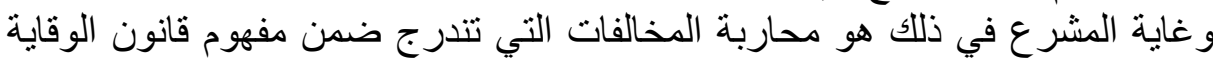

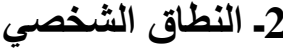

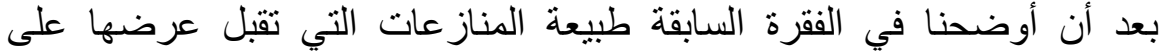

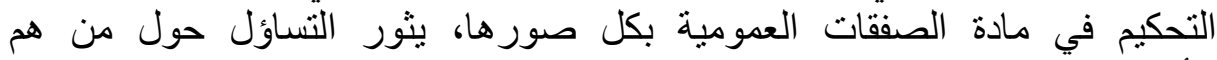

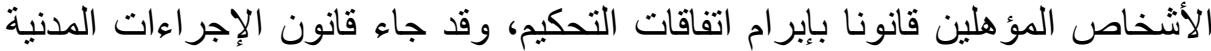

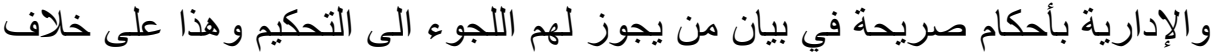

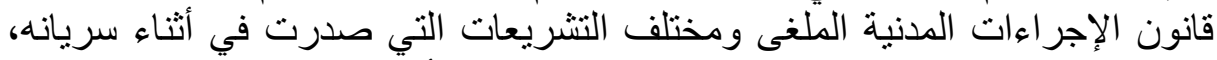

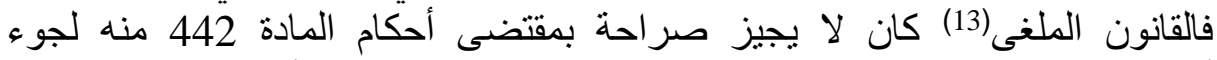
أنخاص القانون العام للتحكيم بعبارتها " لايجوز للادولة ولان للأشخاص الاعنباريين

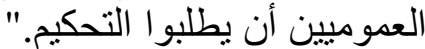
غير أن هذا المنع تم التخفيف منه بموجب النمان المرسوم التشريعي الصادر سنة 1993 تحت رقم 93-09 المؤرخ في 1993/04/25 المعدل والمتمم لقانون الإجراءات 


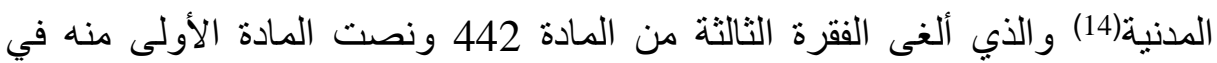

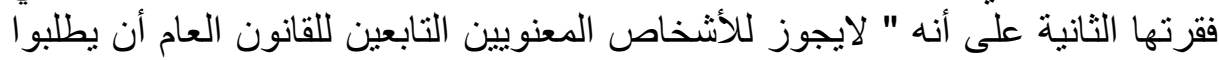

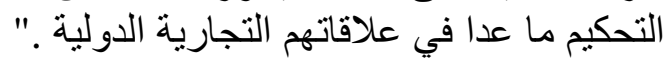

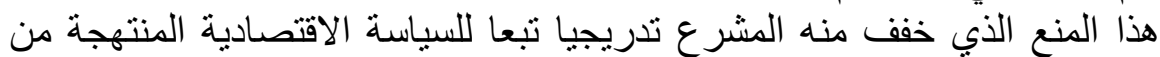

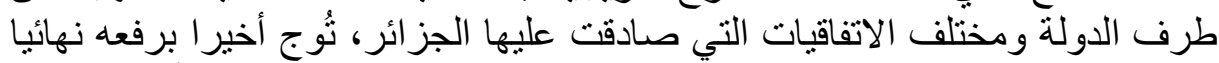

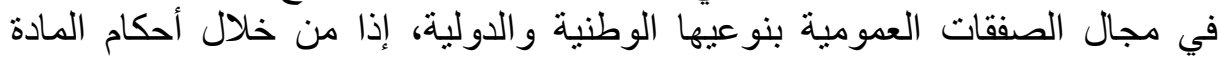

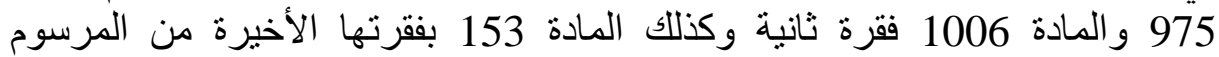

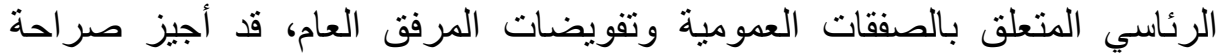

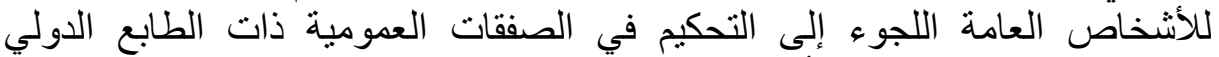

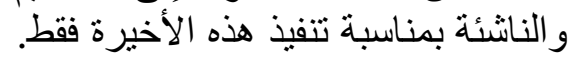
وحتى تطبق هذه الأحكام، يجب أنة أن يكون المتعامل الذبة الذي يتعاقد مع الأشخاص

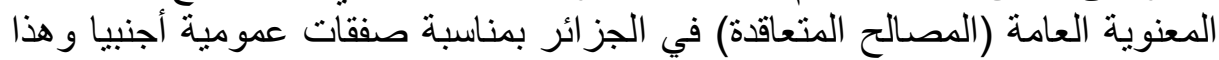

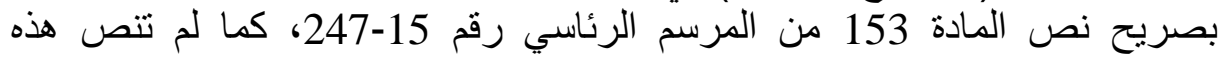

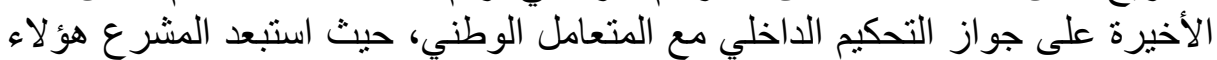

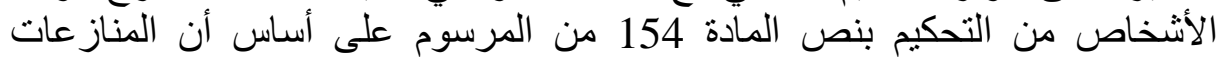

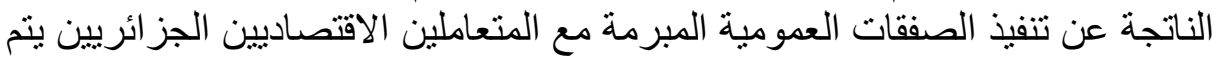

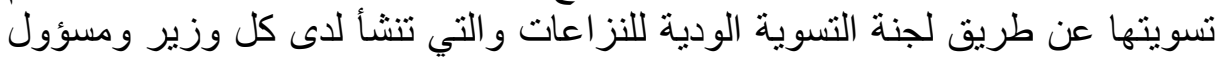

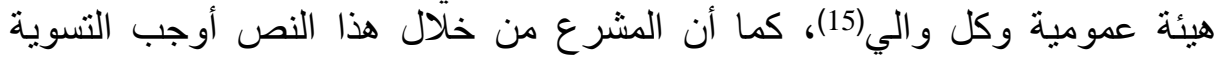

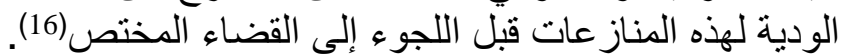

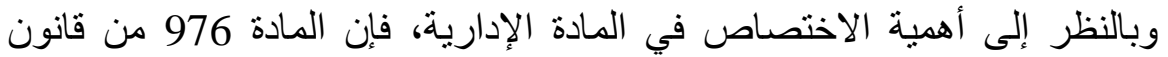

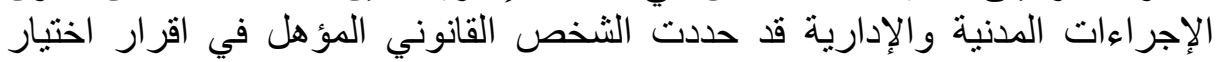

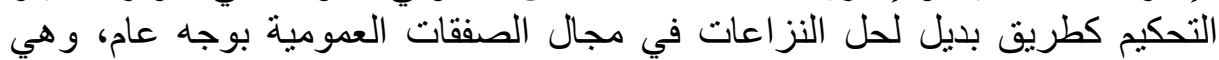

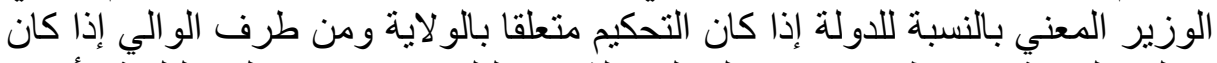

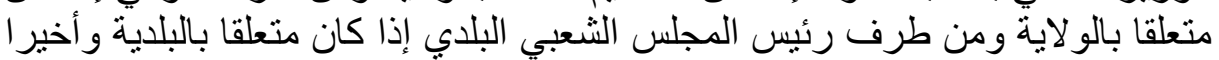

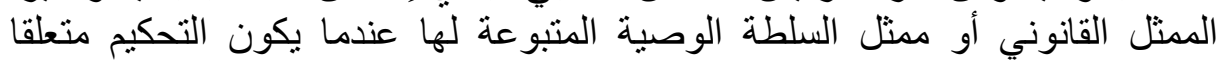
بمؤسسة عمومية ذات صبغة الفية إدارية(17).

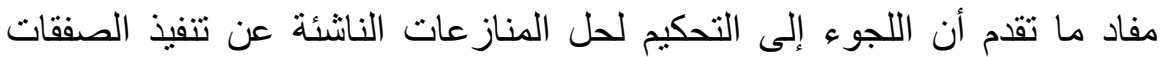

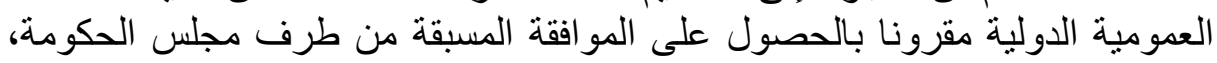

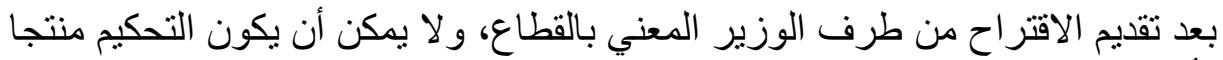

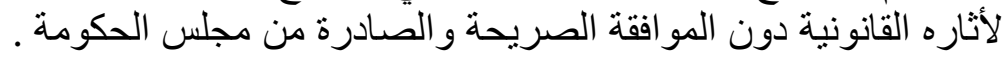

ثالثا: الاتفاق على التحكيم لحل منازعات تنفيذ الصفقات العمومية الدولية

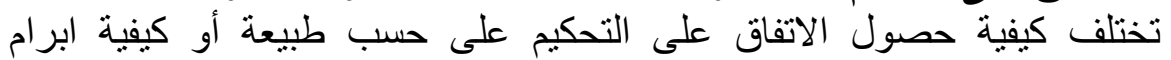

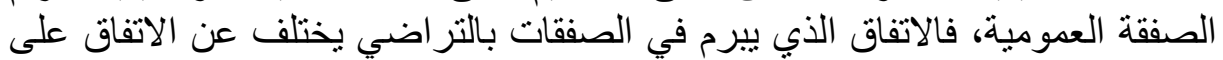

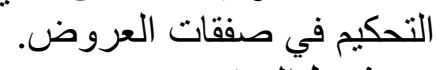
1 - شرط التحكيم

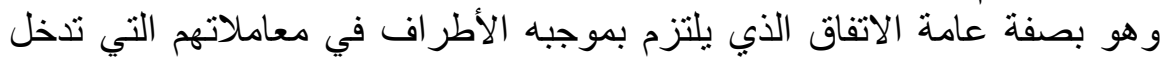

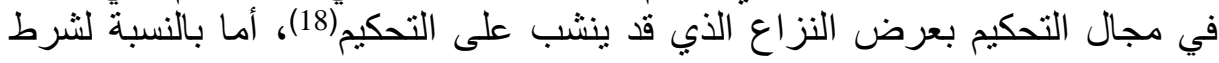

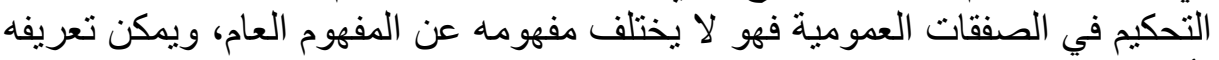

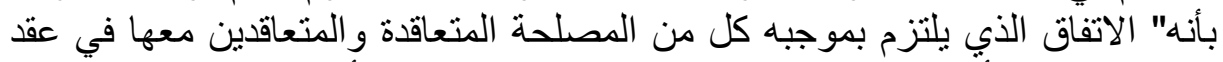

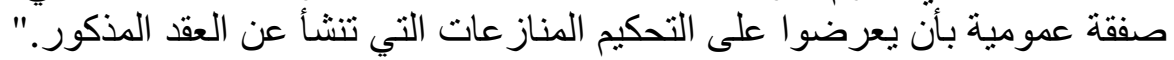

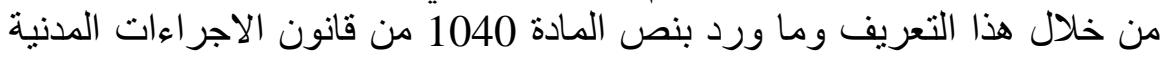

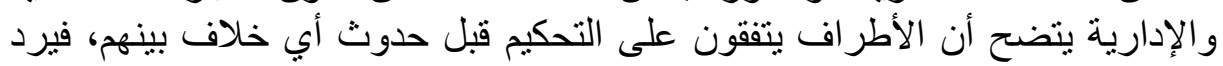


اتفاقهم في هذه الحالة في شكل شرط أو بند من بنود العقد الأصلي وهو الأمر الغالب ـ

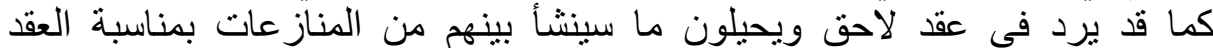

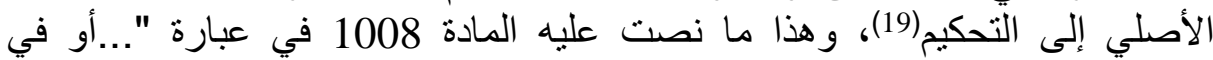
الوثيقة التي تستند إليها." ويكون المميز لثرط التحكيم في كلتا الحالتين، هو ليس وروده في العقد الأصلي

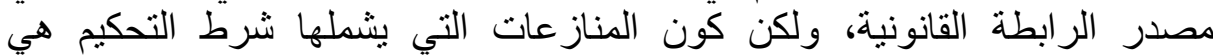

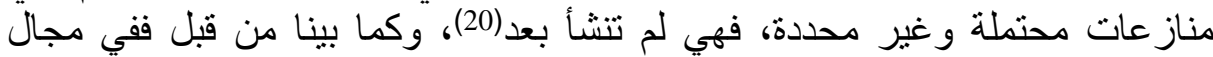

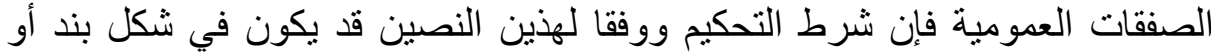

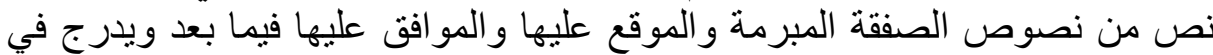

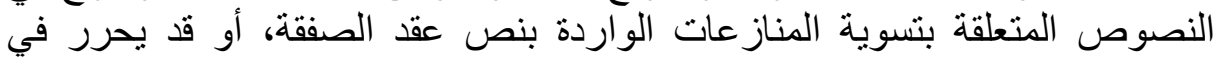
وثثقة لاحقة ولكنها تابعة لها وهي جزء من عقد الصفقة، بحيث يتم الاتفاق فيها على الى التي الفصل في المناز عات التي قد تنشأ مستقبلا عن طريق وني التحكيم(21).

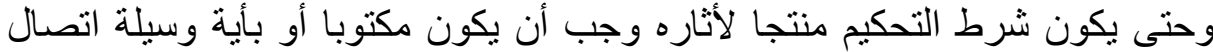

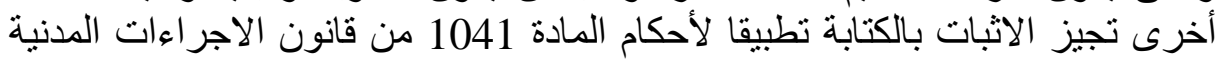

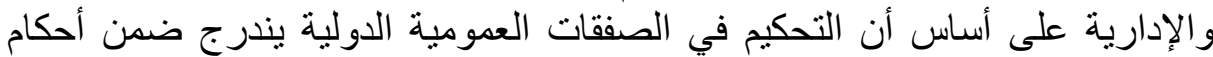
التحكيم التجاري الدولي، وأن يتضمن هذا الاتفاق (الثرط) تعبين التين المحكم أو المحكمين أو تحديد كيفيات تحديدهم.

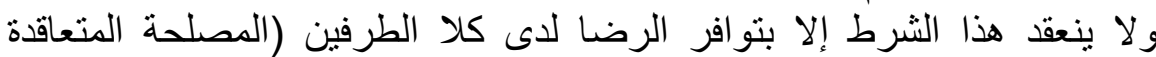

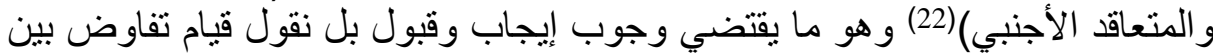

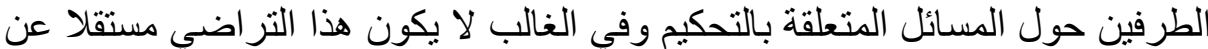

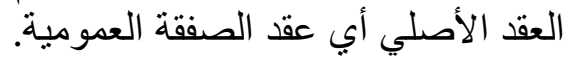

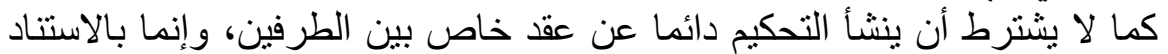

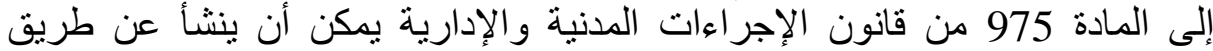

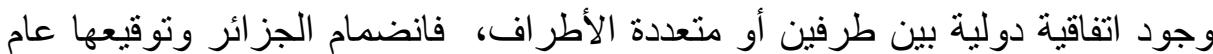

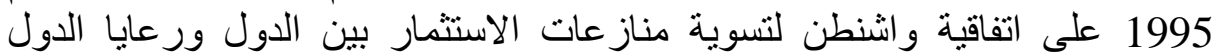

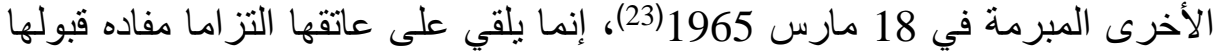

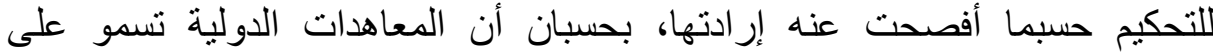

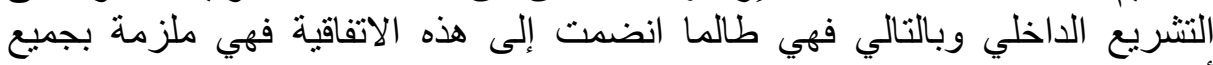

إلى جانب الرضا المعبر عنه صراحة، يجب أن يحصل الاتفاق على محل هذا

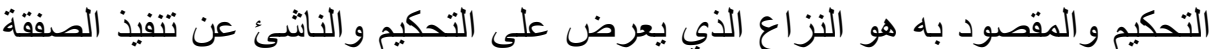

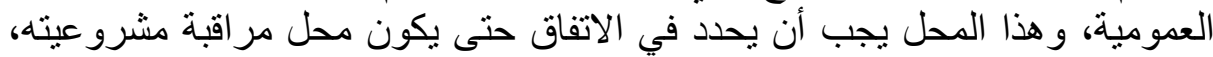

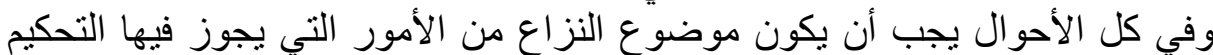

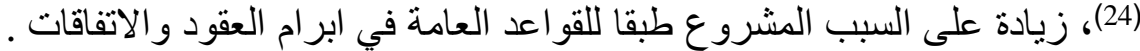

\section{2- الاتفاق على التحكيم ( مشارطة التحكيم)}

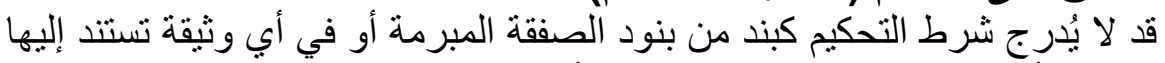

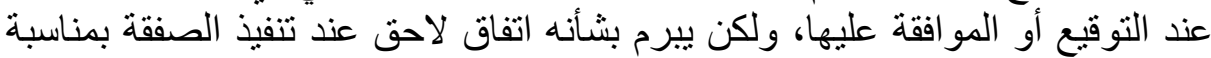
نشوء نز اع بين أطر افها.

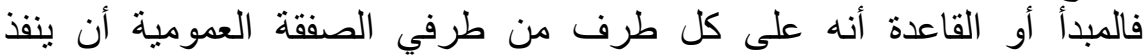

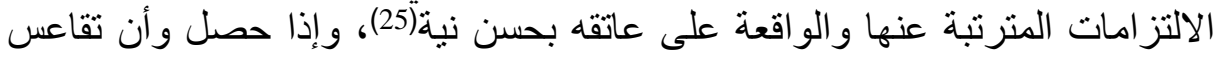

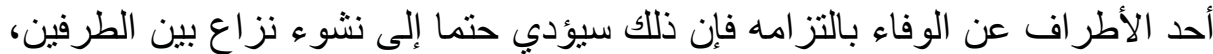

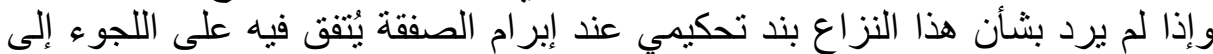
التحكيم فإنه يجوز للطنان هذرفين في هذه الحالة أن بقوما بإبر ام مشارطة التحكيم. 
فمشارطة التحكيم أو اتفاق التحكيم باعتباره اللفظ الذي استخدمه المشرعة الفئ تعني

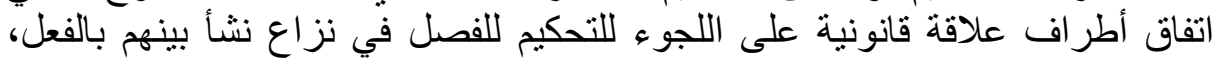

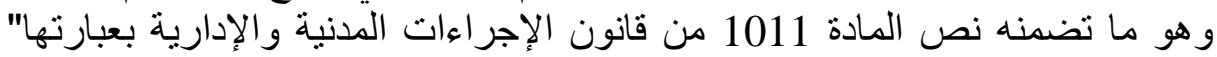

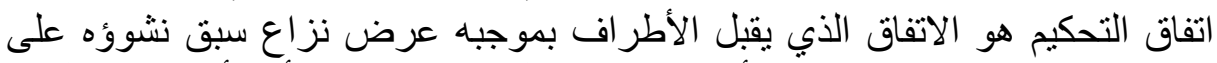

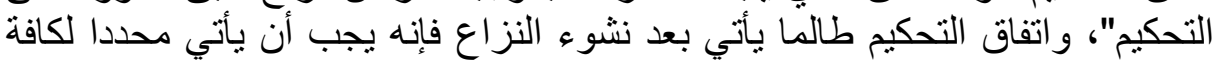

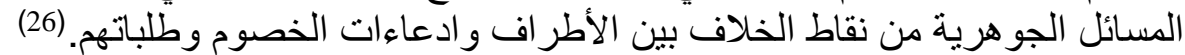

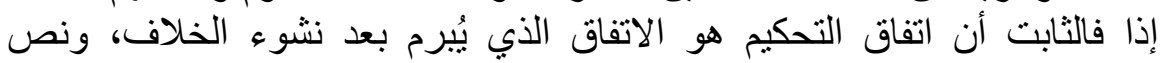

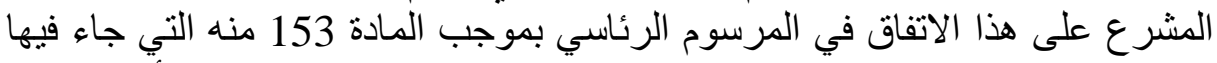

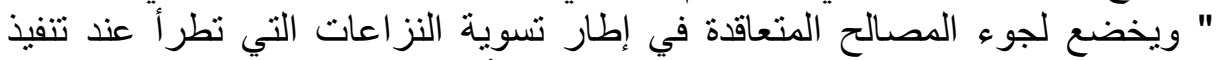

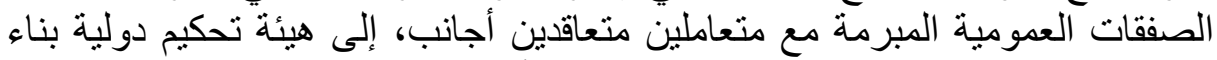

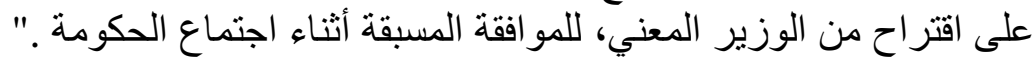

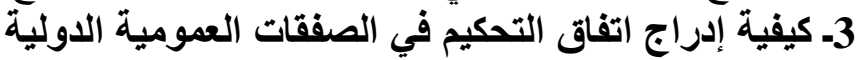

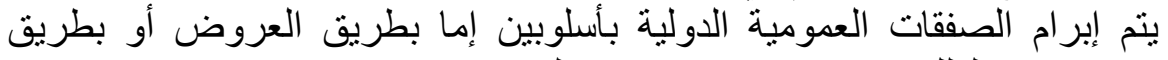

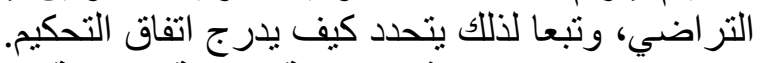

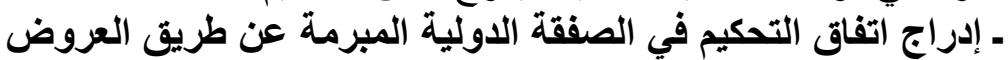

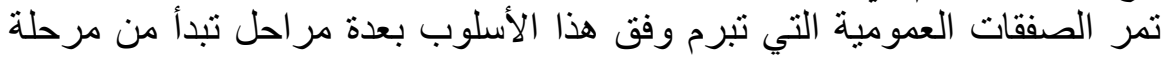

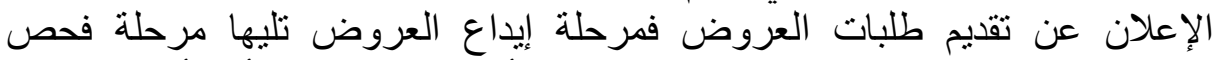

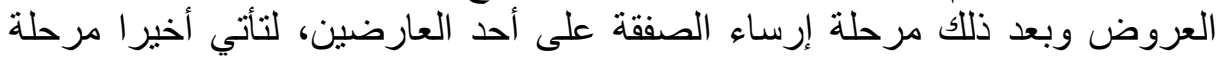

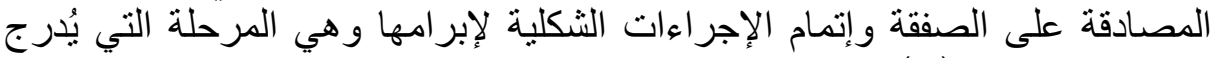

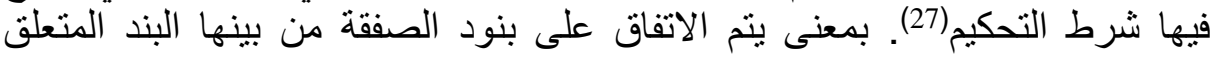

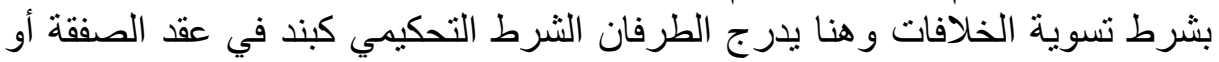

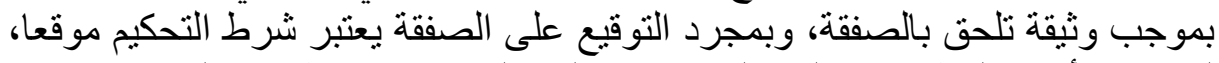

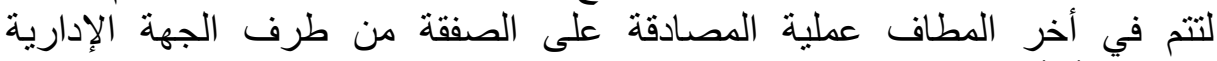

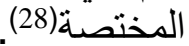

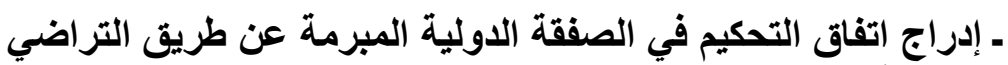

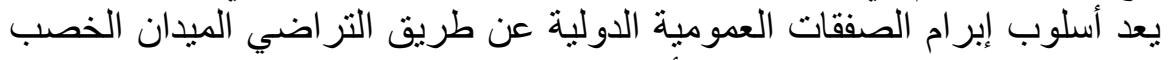

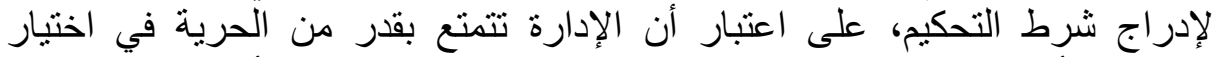

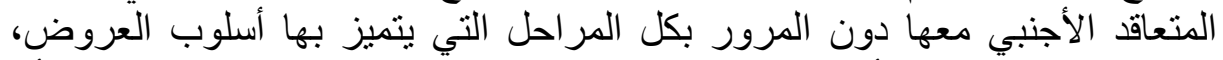

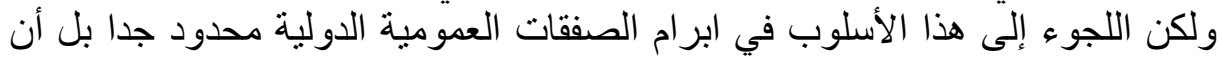

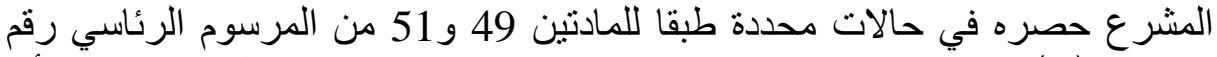
247-15(29)، فيتم إدر اج شرط التحكيم كبند في الصفقة والذي يحصل التفاوض بشأنسانه

ما تجب الإشارة إليه أن اتفاق التحكيم لحل النزاع الناثـئ عن تنفيذ الصفقة بكل حرية.

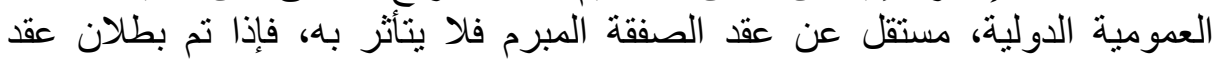

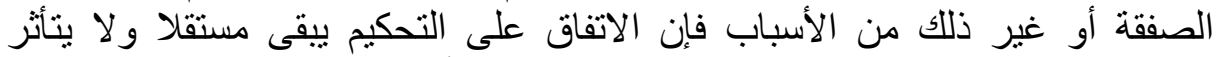

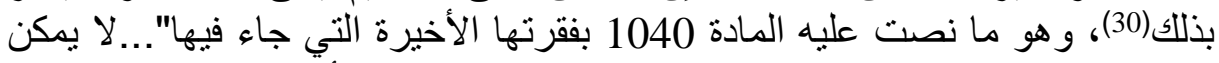
الاحتجاج بعدم صحة اتفاقية التحكيم، بسبب عداء عدم صحة العقد الأصلي."

المحور الثاني: النظام الاجرائي للتحكيم في منازعات تتفيذ الصفقات العمومية

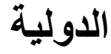

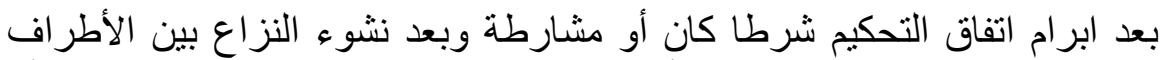

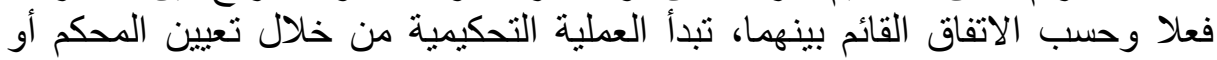

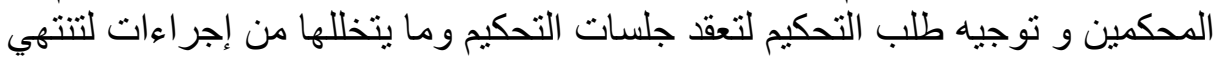


في النهاية إلى صدور حكم التحكيم ثم تليه مرحلة الاعتر اف وتتفيذ الحكم التحكيمي، كل هذه المر احل نتناولها بايجاز في فقرات التهات متتالية .

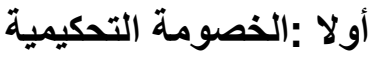

تبدأ اجراءات التحكيم عند وقوع خلاف بين أطر اف اتفاق التحكيم، حيث يبدأ أحد الأطر اف في إعلان رغبته في تحريك إجراءات الخصومة التهات التحكيمية والتي حتما تبدأ

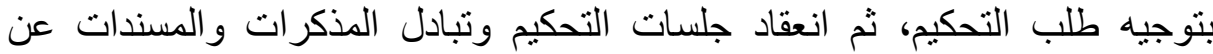

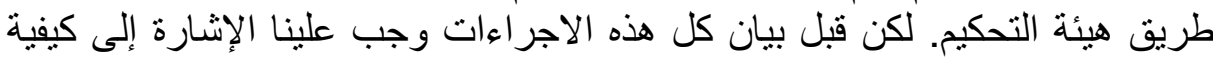
تعبين المحكمين وتشكيلة هيئة التحكيم. فئن 1- تشكيل محكمة التحكيم

يقصد بتشكيل هيئة أو محكمة التحكيم الدولي اختيار الثخص أو التهي التشخاص الذين

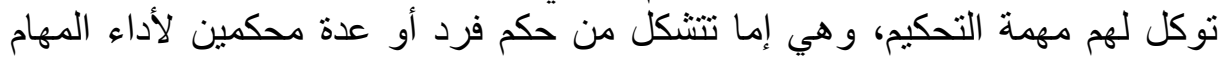
المنوطة بهم وفق مجمو عهة من القيم، وهئ القو اعد. ـ تعيين المحكم أو المحكمين

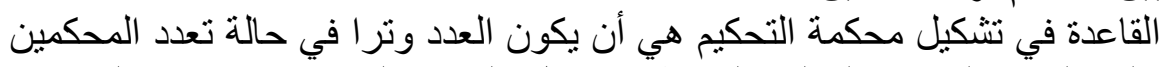

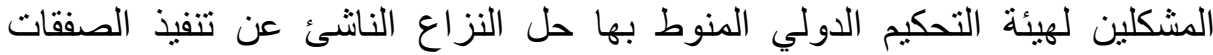

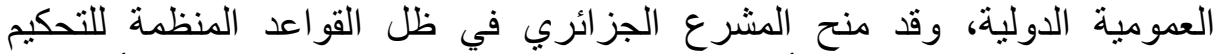

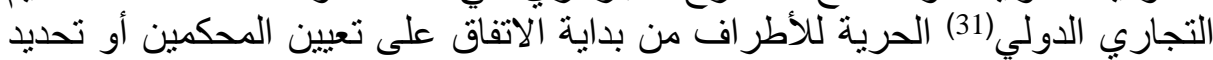
طريقة تعينهم و التي تتمثل في الآتي:

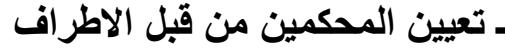

اتجه المشرع على غرار مختلف التشريعات الدولية إلى إعطاء الحرية الكاملة

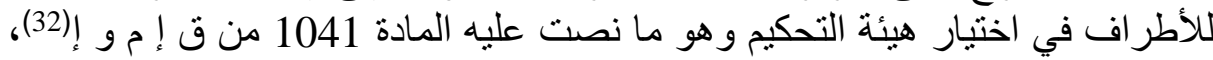

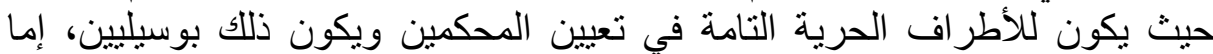
بتعيينهم مباشرة أو تحديد شروط تعيينهم وشروط عزلهي لهم واستبدالهم ويكون ذلك في الكي

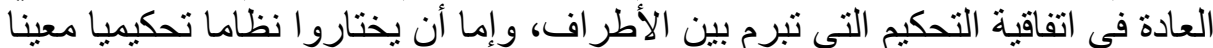
يتم اعتماده في هذه العمانة العملية.

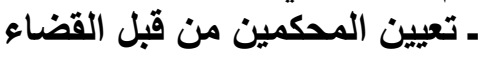
يظهر في هذه الحالة الدور المساعد للقضاء في العملية التحكيمية ويكون ذلك الكين عندما لايوجد أي نص اتفاقي لهذا التعيين، وكذلك عندما تنشأ صعوبة في التعبين

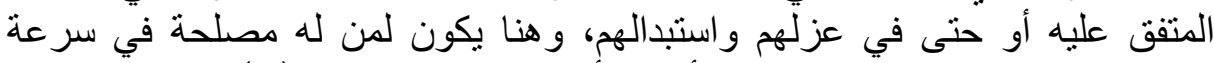
انطلاق وسيرورة العملية التحكيمية أن يلجأ إلى القضاء مباثنرة، (33) وفي هذه الحالة فرقت المادة السالف ذكر ها بين نو عين من التحكيم.

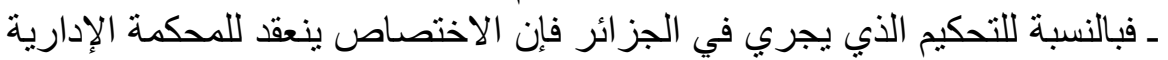

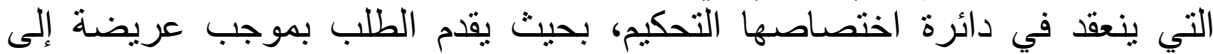
رئيس المحكمة المختصة للفصل في هذا التعيين.

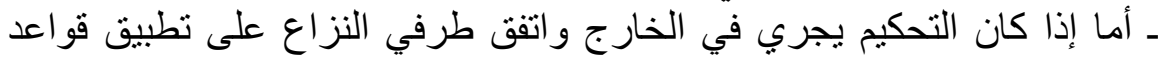

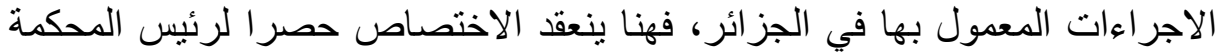

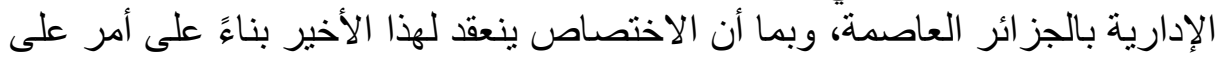

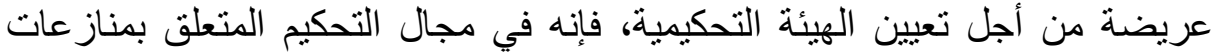

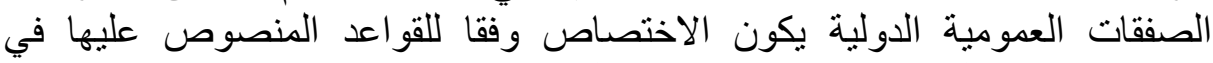

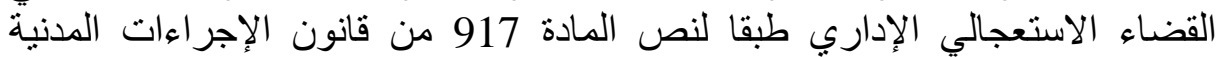

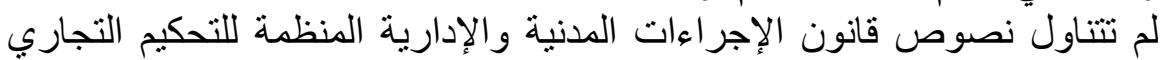

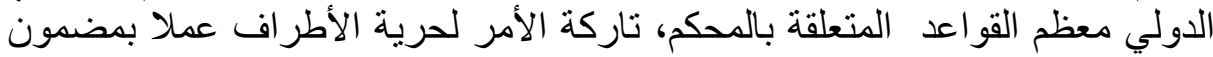


المادة 1041 منه التي تطبق في حالة عزل واستبدال المحكمين، ولهذا قلنا بأن اختيار

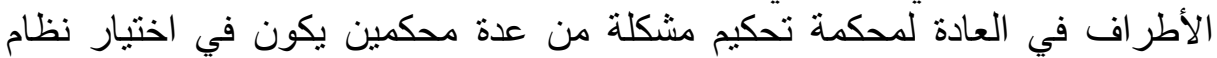
تحكيمي معين أو حتى اللجوء إلى مئى مركز تحكيم (تحكيم مؤسسي) ليتولى فئ العملية التحكيمية منذ بدايتها حتى نهايتها (35).

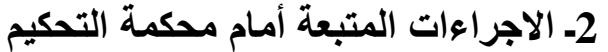
ـ القانون الواجب التطبيق على الاجراءعاء التمات المتبعة أمام محكمة التحكيم

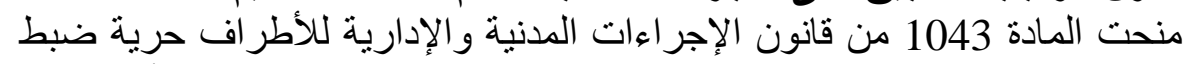

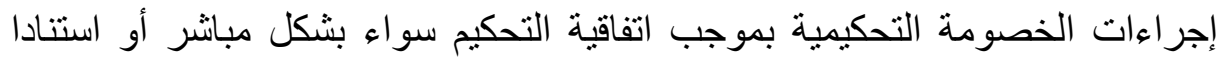

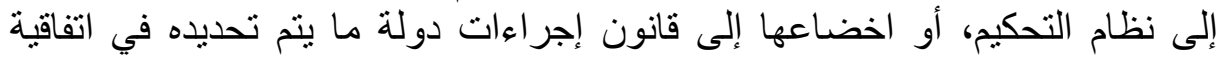

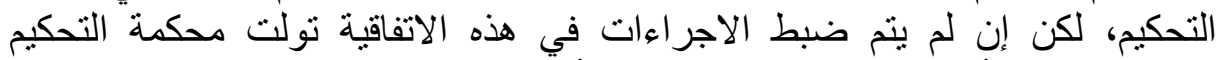

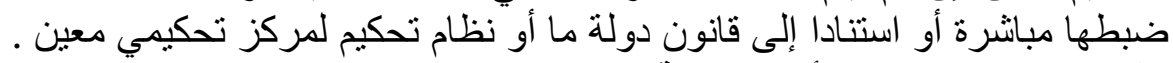

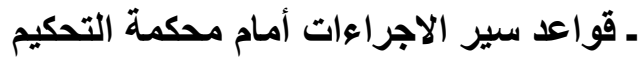

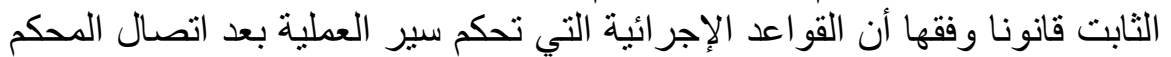

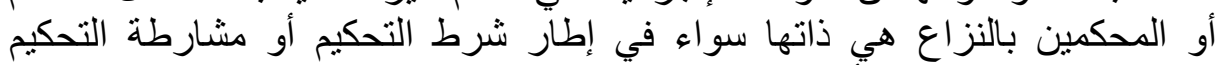
وتتمثل هذه القو اعد في الأتي:

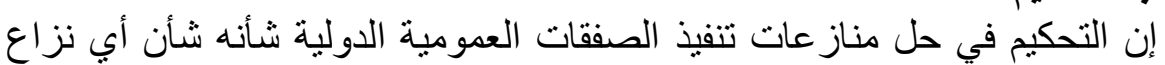
ـ طلب التحكيم

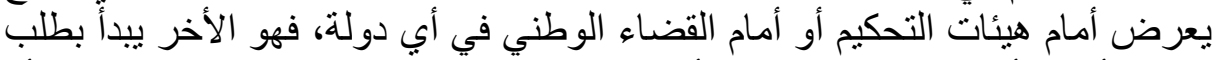

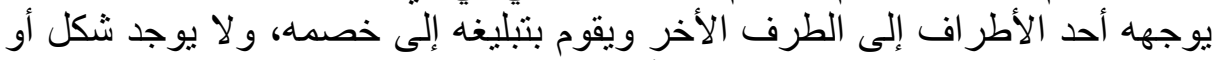

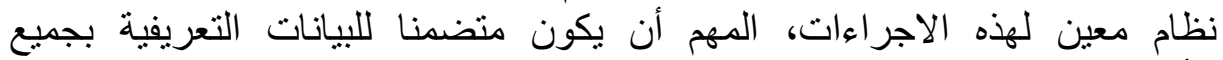

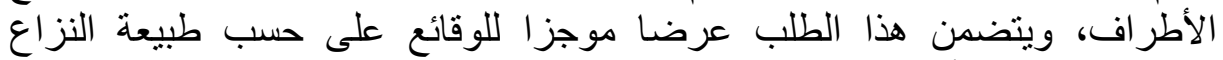

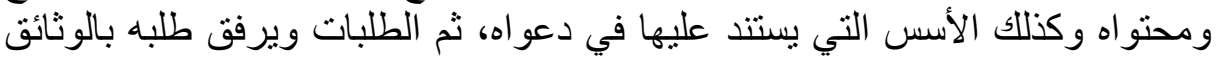

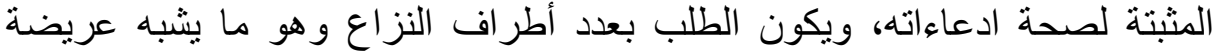

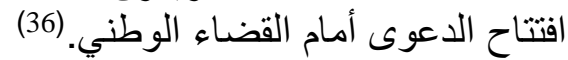

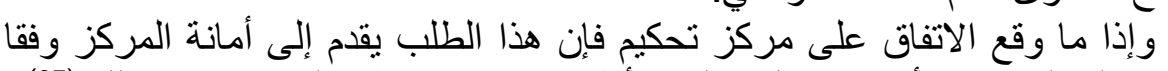

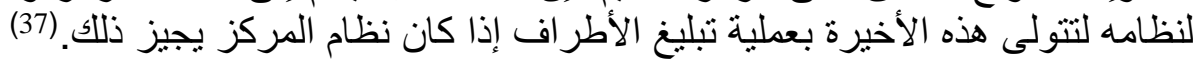
يتم عقد الجلسات في المكان و الزمان وان واللغنة التي حصل الاتفاق عليها أو التي

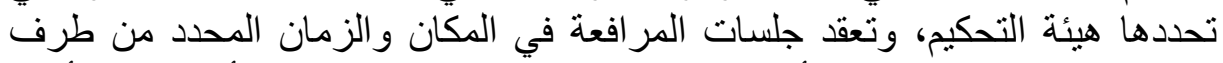

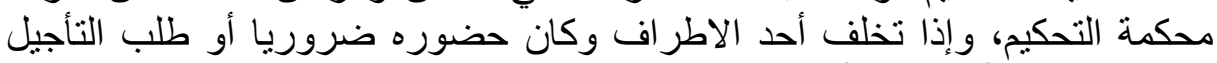
فيكون للمحكمة أن تقوم بتأجيل الجلسة إلى جلسة لاحقة تحدان التحد تاريخها ومكانها .

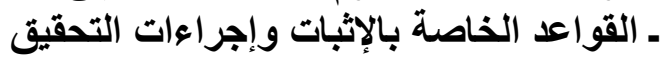

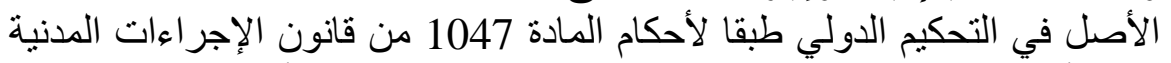

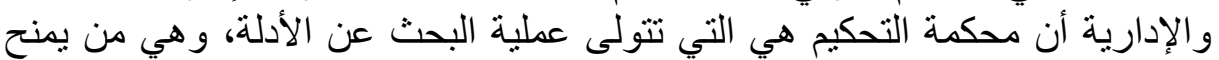

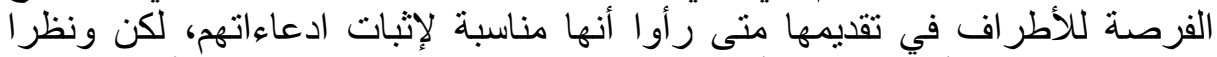

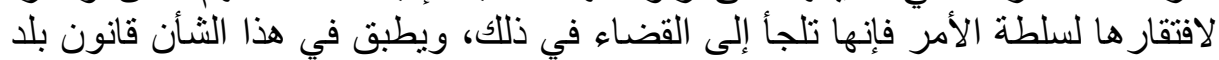

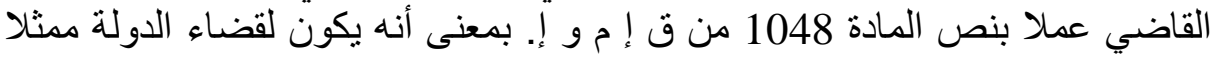

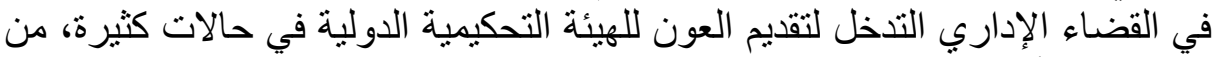

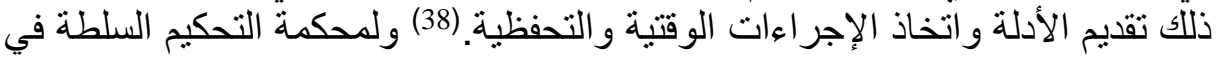

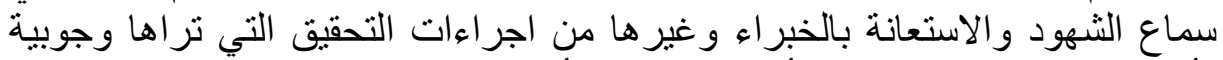

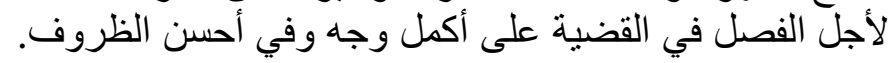


ـ التدابير التحفظية والمؤقتة

عرفت المادة 17 فقرة 2 من قانون اليونستر ال النموذجي لسنة 1985(39) بالصيغة

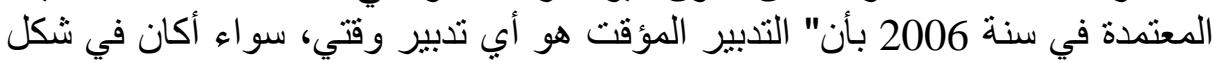

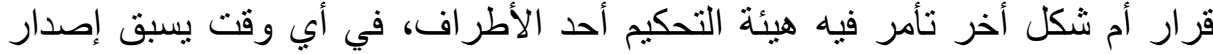

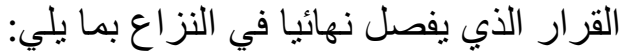
أ ـ أن ييقى الحال على ماً هو عليه أو يعيده إلى إلى ما كان عليه إلى حين الفصل في

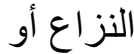

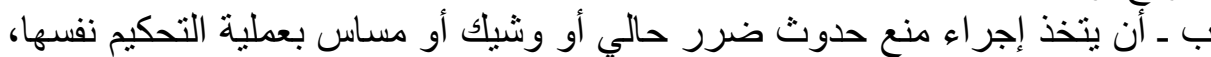

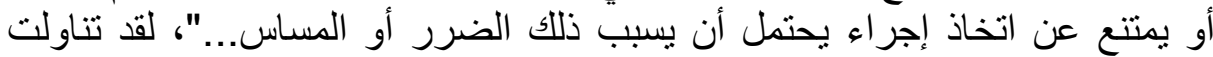

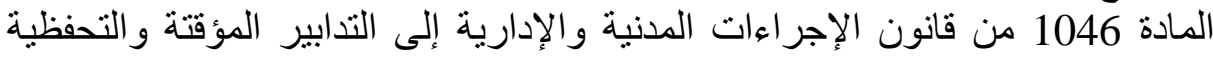

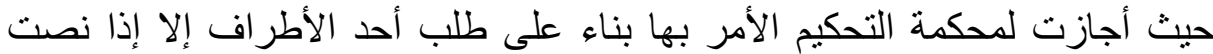

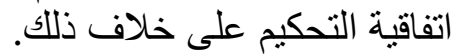
و إذا لم يقم الطرف المعني بتنفيذ هذا التدبير إراديا، جاز لمحكمة التحكيم أن تطلب

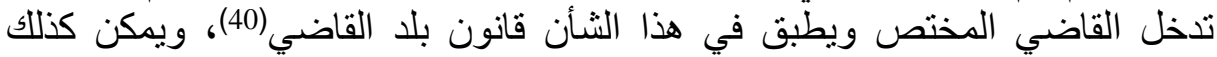
لمحكمة التحكيم أو القاضي أن يُخضع التدابير المؤقتة أو التحفظية لتقديم الضمانيات

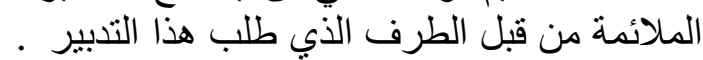

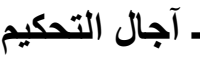

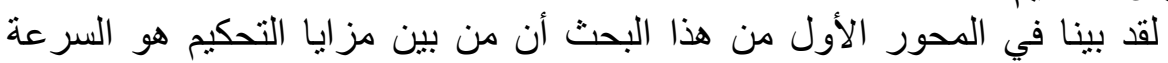

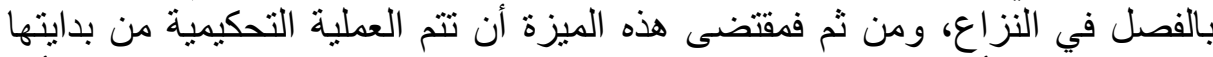

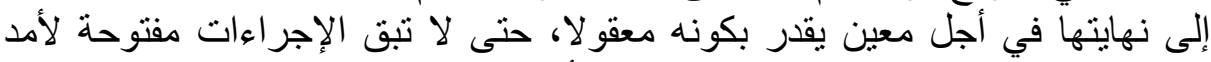

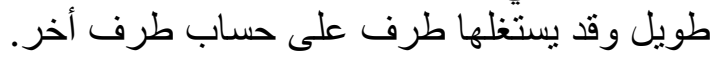
ثانيا: الحكم التحكيمي 1- انتهاء الخصومة التهي التحكيمية وآثار ذلك:

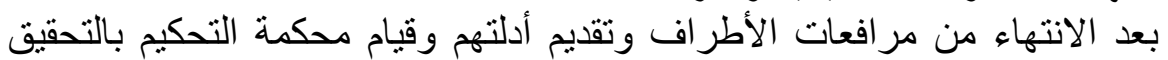

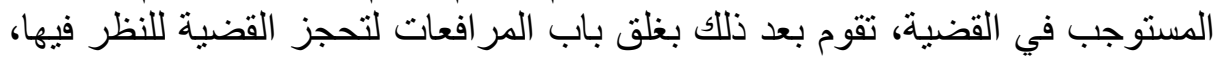

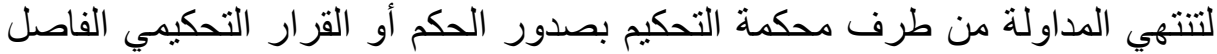
في النزاع المعروض عليها.

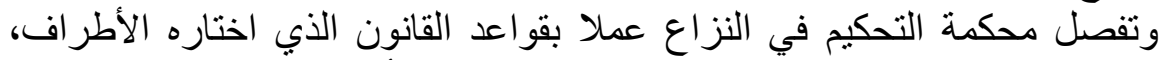

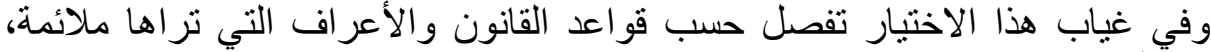

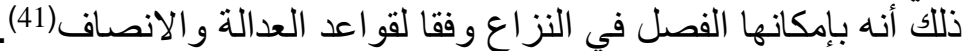

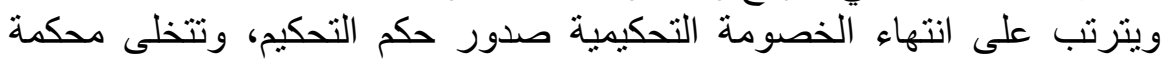

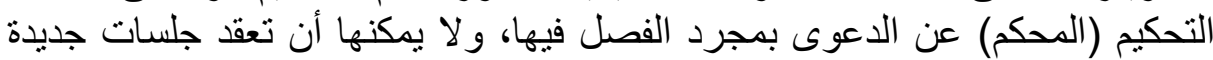
تحت أي مسمى عدا ما تعلق بتصحيح الأخطاء المادية في الأحكام وكذلك تفسير لأها. 2- 2- 2 أحكام الحكم التحكيمي ـ كتابة حكم التحكيم: تشترطم احمي معظم القوانين الوطنية والدولية أن يكون حكم التحكيم

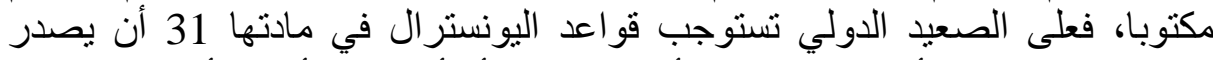

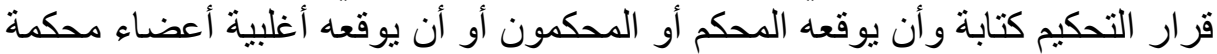

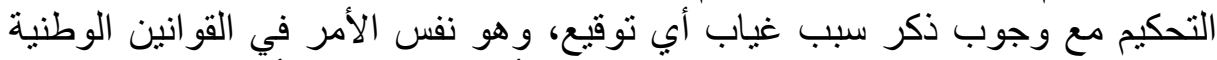

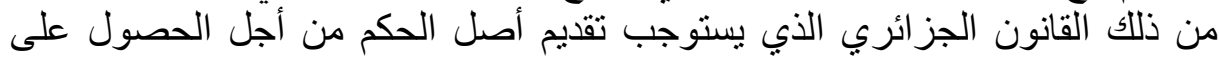
الاعتر اف به و الحصول على الصيخة التنفيذية. (42)

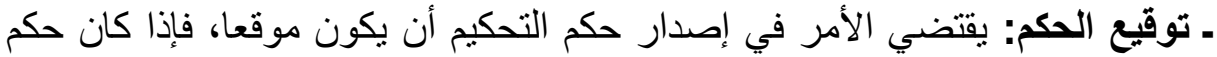
التحكيم فرديا فعلى المحكم الفرد أن يوقعه، أما إذا كانت هيئة التحكيم مشكلة نشكيلة 
جماعية فيقضي توقيعه من جميع المحكمين أو على الأقل الأغلبية مع ذكر سبب عدم

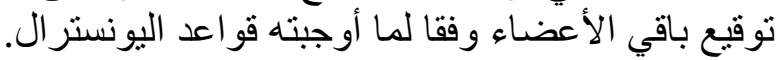

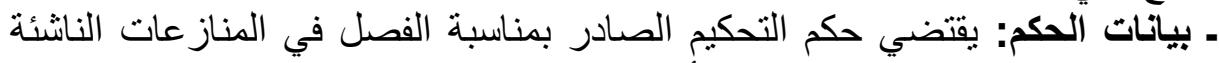

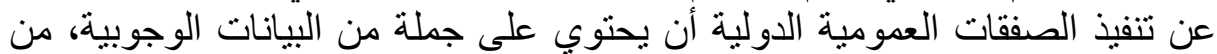

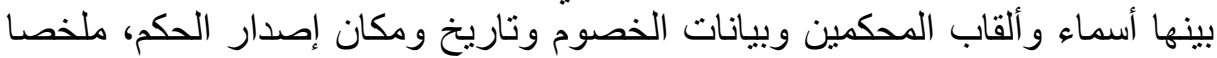

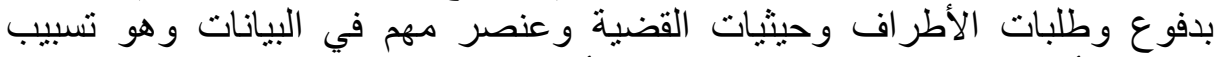

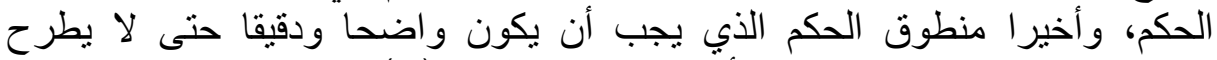

إنكالات تتعلق بتفسيره وما من شأنهة تعطيله عن التنفيذ.

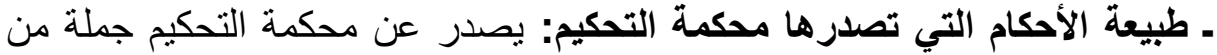

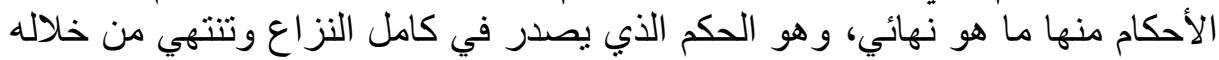

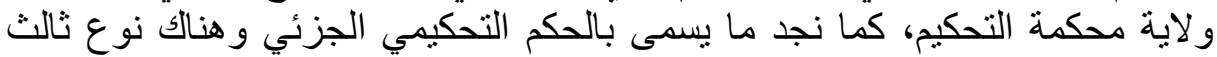

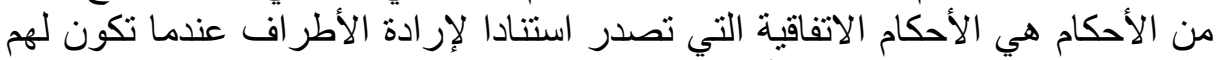

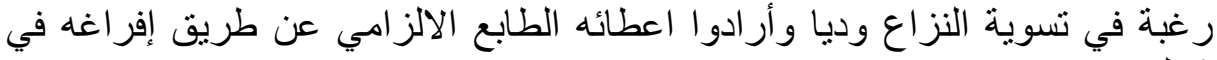

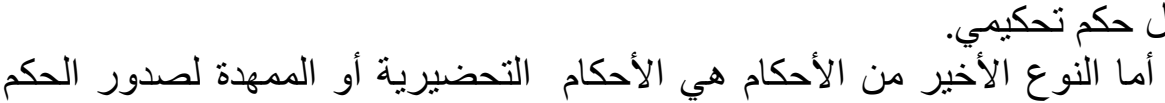

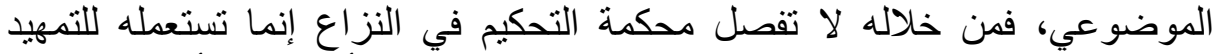

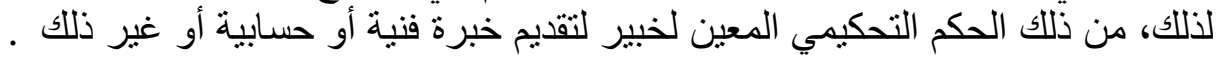

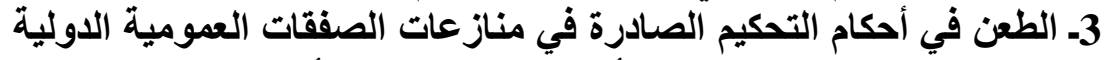

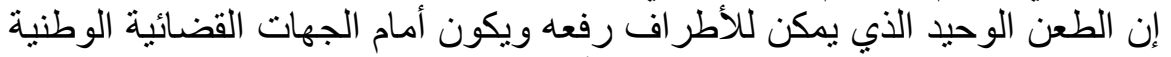

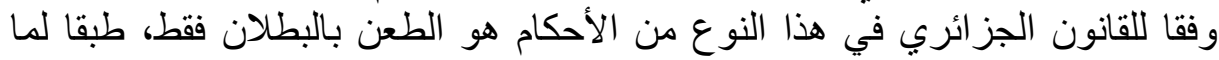

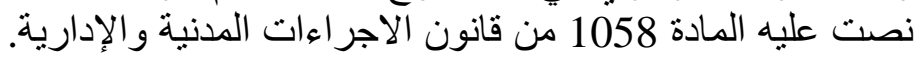

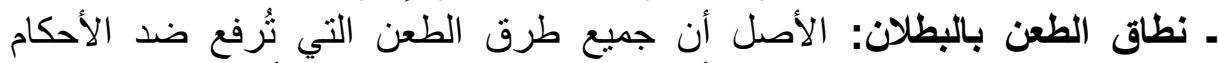

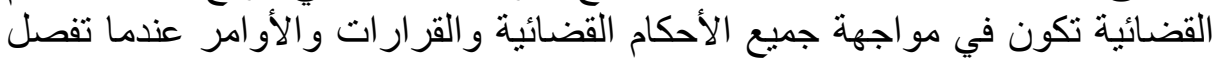

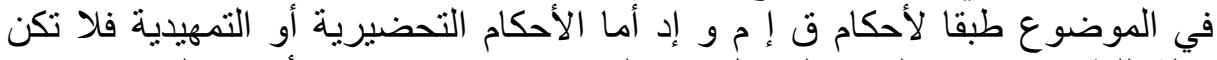

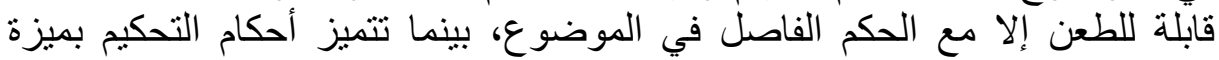

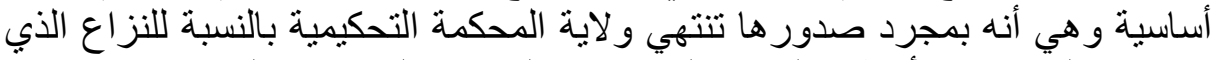

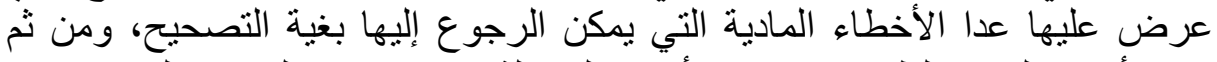

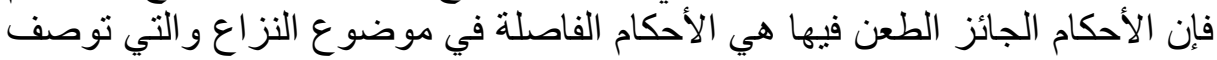
بالأدولية والتي تصدر الإن عن هيئة تحكيم دولية.

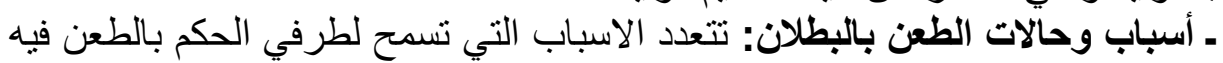

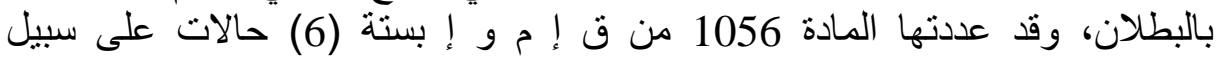

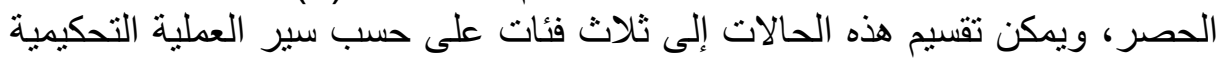

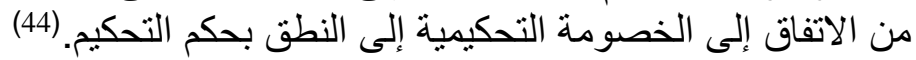

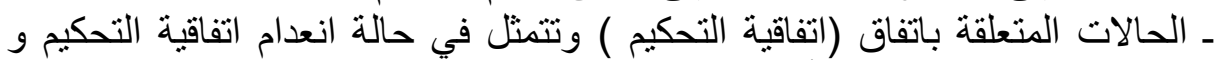

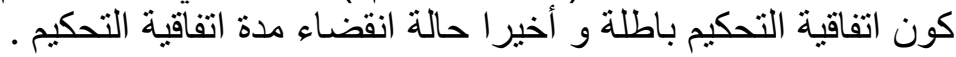

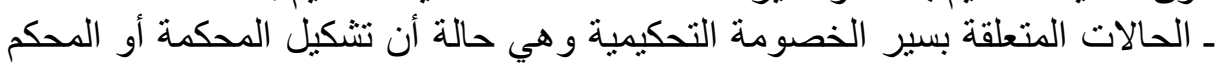
الوحيد جاء مخالفا للقانون وحالة القالة عدم مر اعاة محكمة التحكية التحكيم مبدأ الوجاهية.

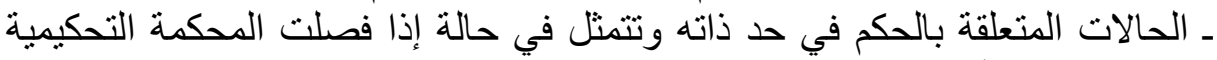

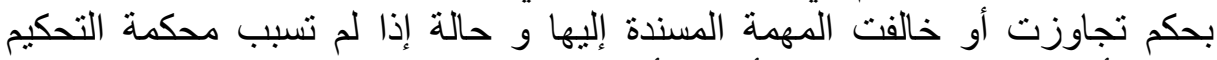
حكمها أو إذا وجد تناقض في الأسباب أما الحالة الثالثة هي حالة إذا لإلة كان حكم التحكيم 
ثالثا: الاعتر اف بأحكام التحكيم وتنفيذها

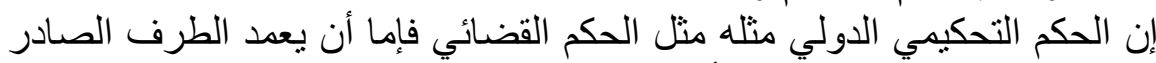

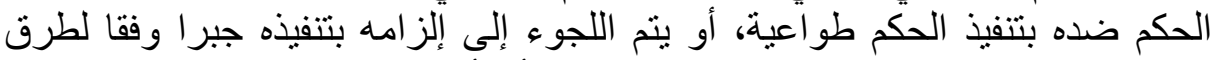

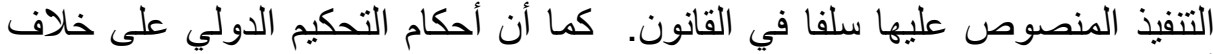

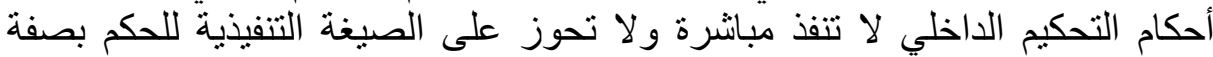

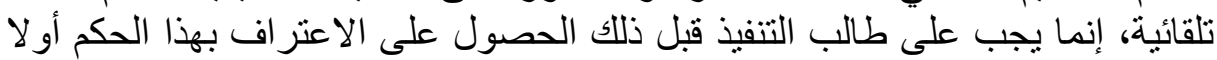

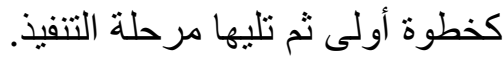
1- الاعتراف بالحكم التحكيمي

الاعتر اف يعني إقرار القضاء الرئي الرسمي في الدولة بأن الحكم التحكيمي قد صدر

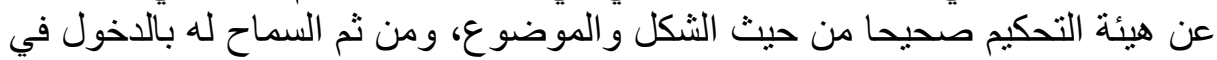
النظام القانوني لدولة القاضي لكونه جاء لكاء مطابقا لقو اعدها.

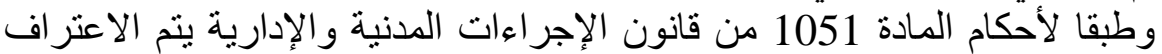
بحكم التحكيم الدولي إذا تحقق شرطاد التهان أساسيان هما:

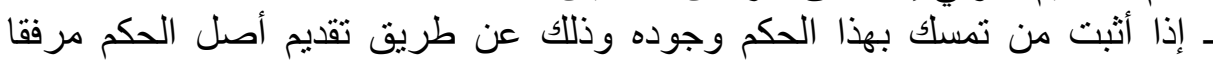

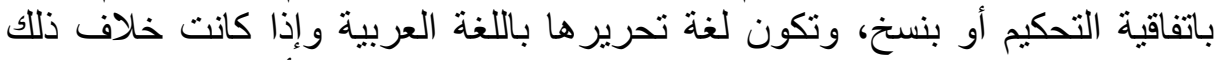

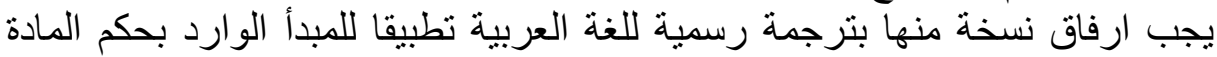

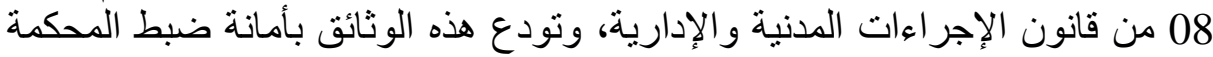

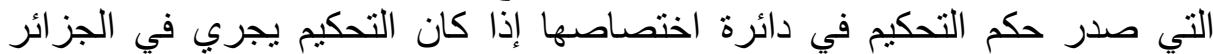

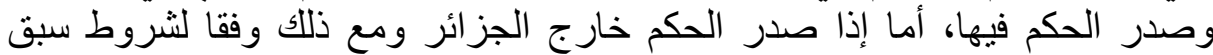
بيانها يعتبر دوليا وليس أجنبيا فيقدم الطلب أمام محكمة محل تنفيذ الحكم وذلك من فن طرف من يهمه التعجيل.

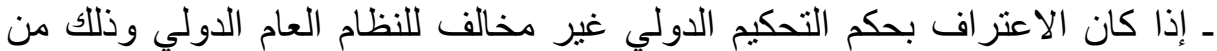

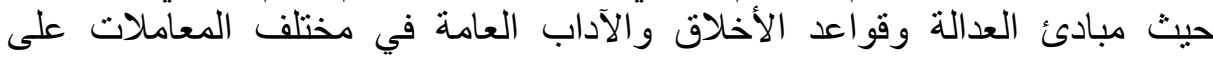
المستوى الدولي.

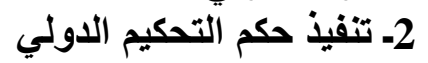

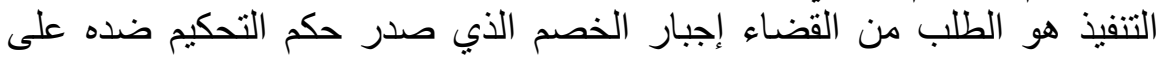

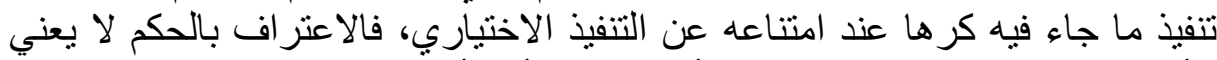

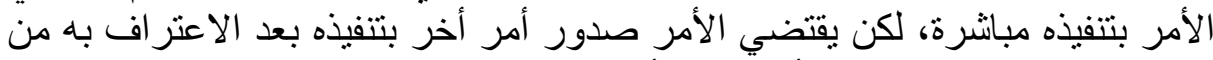

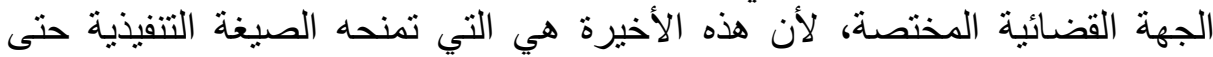

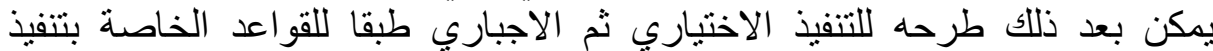

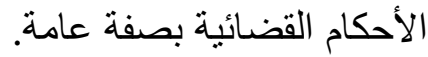

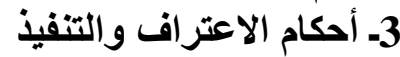

يقدم طلب الاعتر اف والت التفيذ بموجب إنب عريضة متضمنة البيانات اللازمة كغير ها من العر ائض طبقا للمادة 311 من ق إ م و إ والمتعلقة بتقديم العرائض أمام رئيس

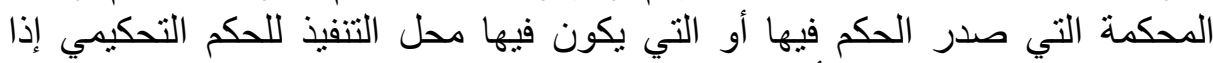

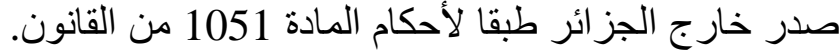

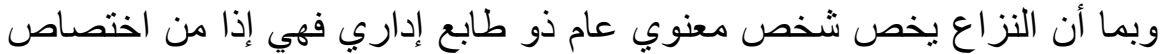

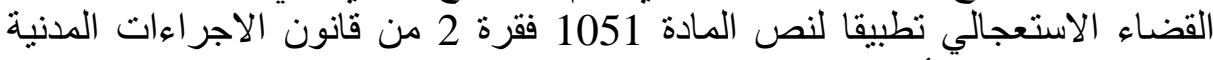

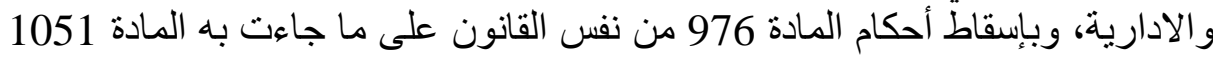

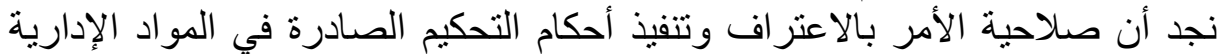

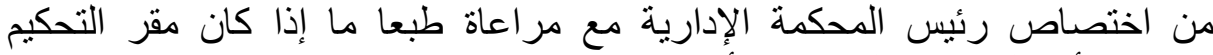
بالجز ائر أو بالخار جائن وذللك وفق الأتي: 


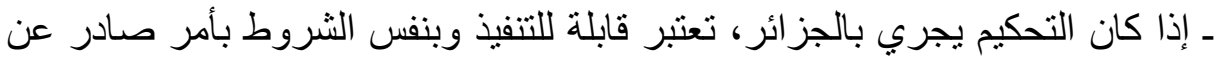

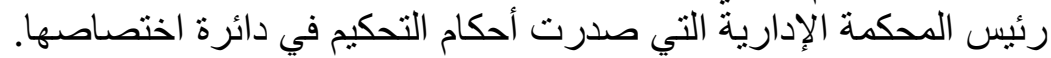

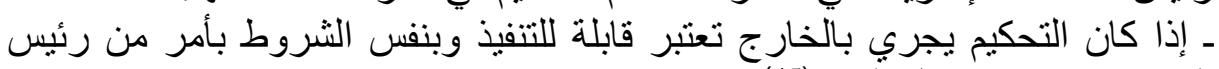

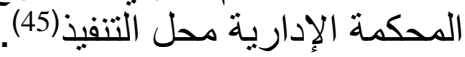

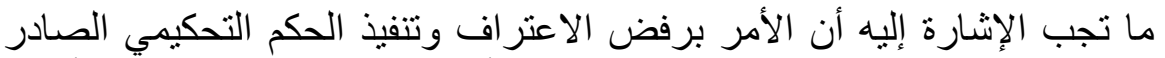

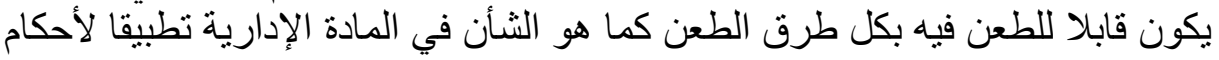

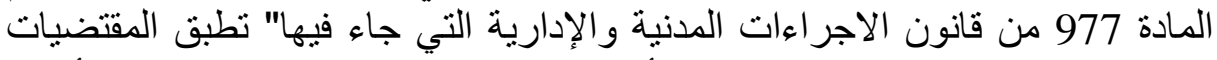

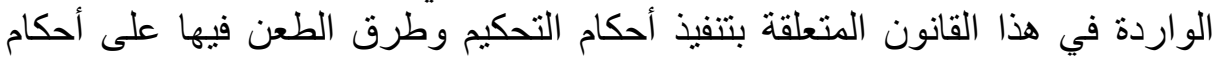
التحكيم الصنادرة في المادة الإدارية."

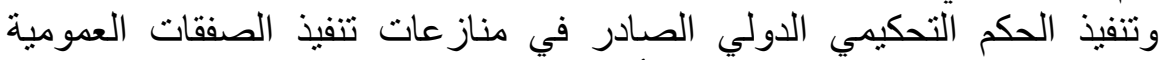

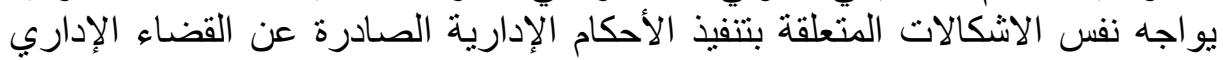

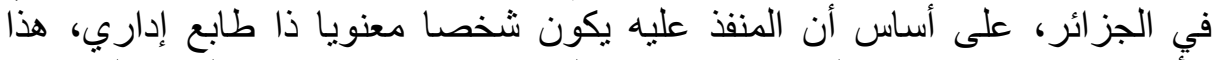

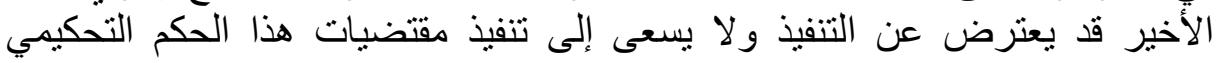
المعترف به و المستوجنب عليه تنفيذه

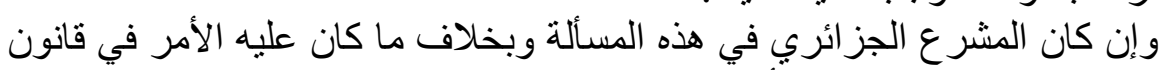

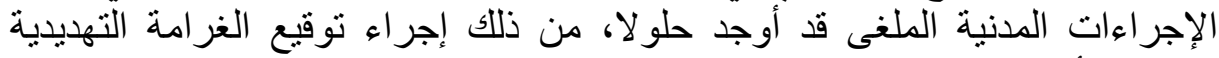

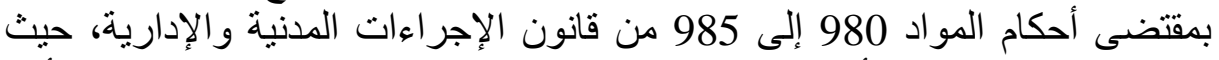

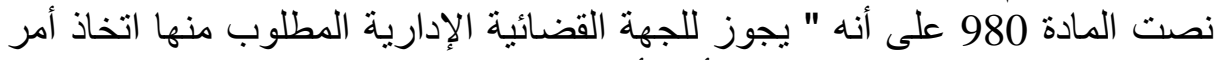
بالتنفيذ وفقا للمادتين 978 و979 أن تأمر بغر امة تهديدية مع تحديد تاريخ سرية الأبران مفعو لها." بل وإلى جانب إجراء الغرامة التهديدية أوجد المشرع فيما بتعلق بالأحكام

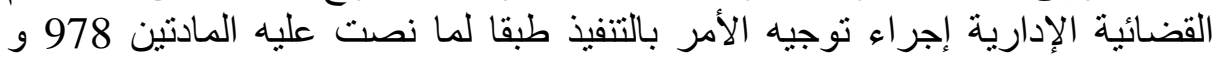

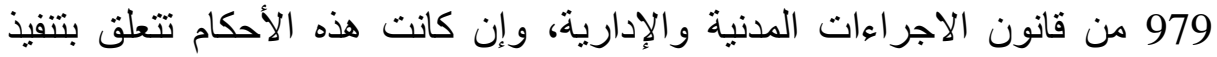

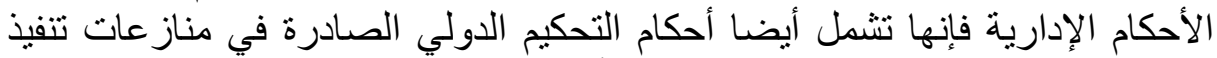

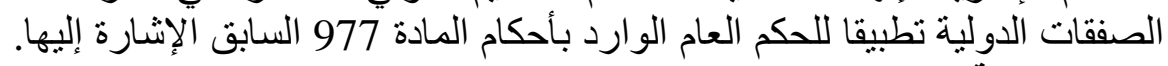

لقد تبين من خلال هذا البحث أن التحكيم في المناز عات الناشئة عن تتفيذ الصفقات التهات

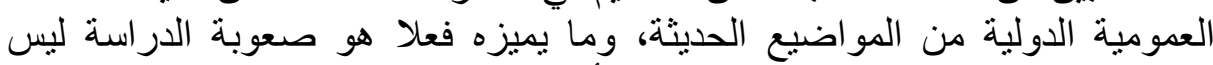

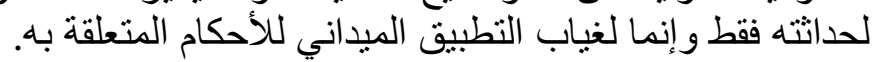

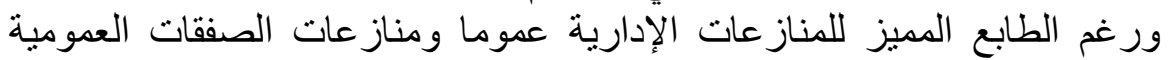

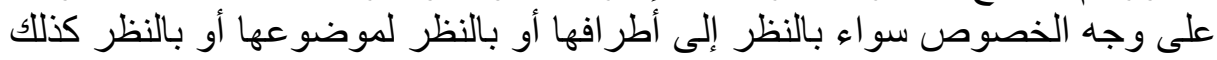

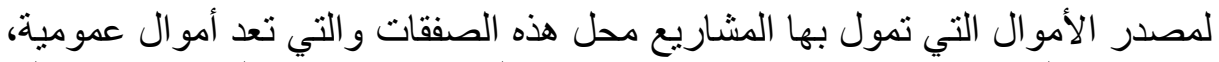

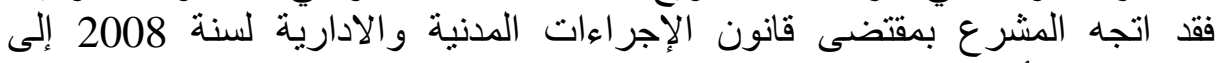

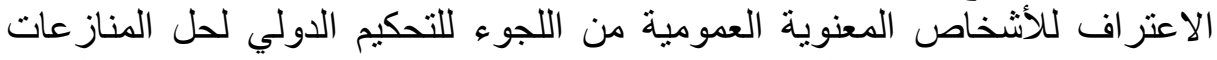

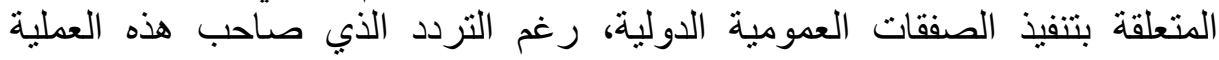

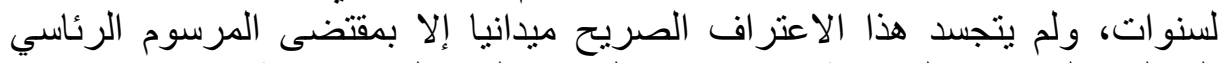

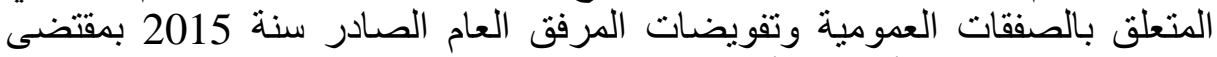
المادة 153 بفقرتيها الأولى والأخيرة.

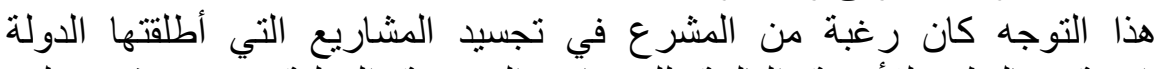

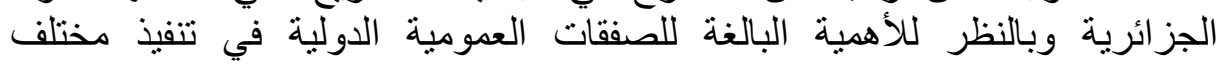

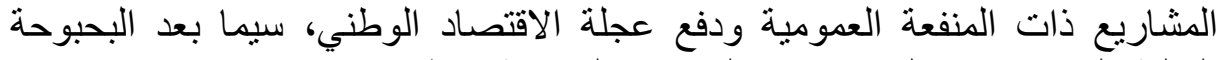

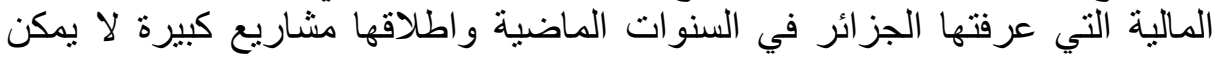


تجسيدها بو اسطة متعاملين جز ائريين لأسباب مختلفة، ومن ثم كانت الحاجة لمتعاملين

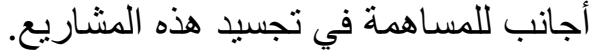

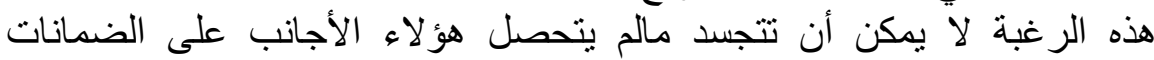

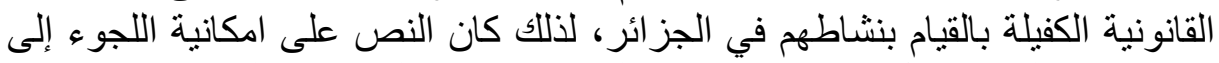

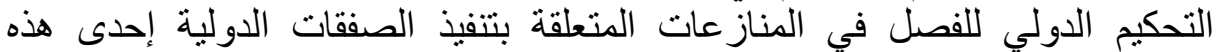
الضمانات التي تجسدت فانونا.

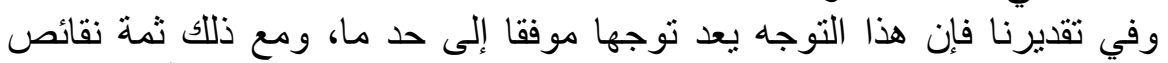

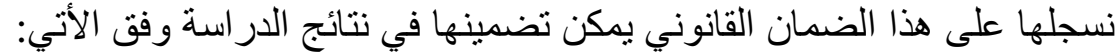

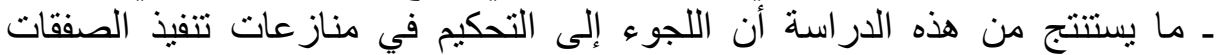

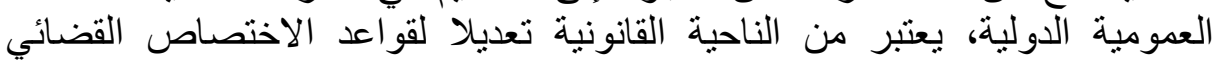

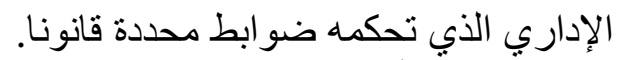

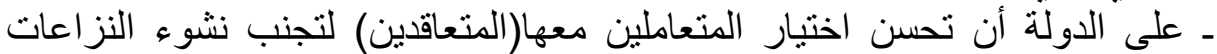

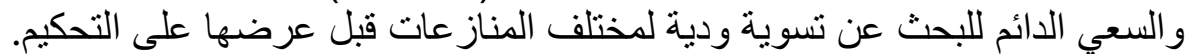

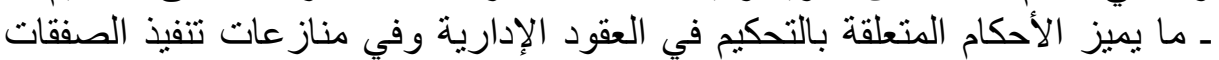

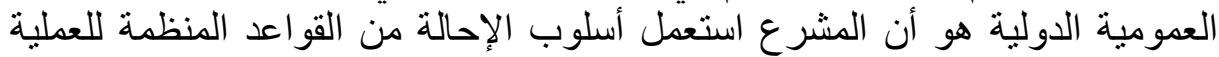

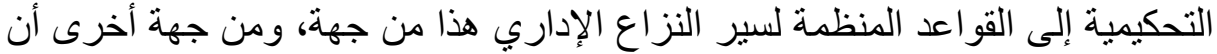

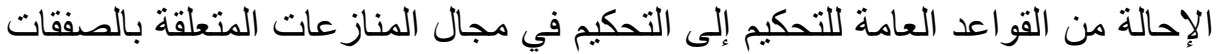

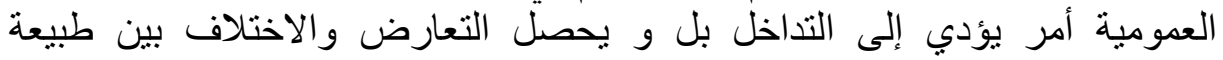

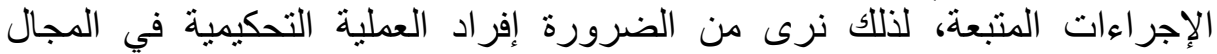
الإداري والصفقات العمومية بنصوص الإئ خاصة مستقلة عن القواعد الأخرى من خلال

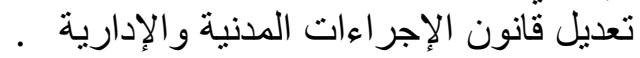

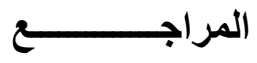

1- المرسوم الرئاسي رقم 15-247 يتضمن تنظيم الصفقات العمومية وتفويضـات المرفق المبن

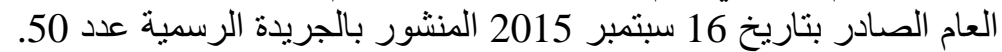

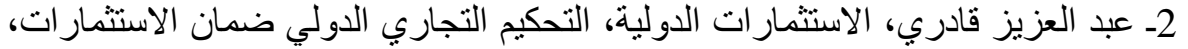

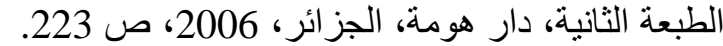
3ـ أحمد أبو الوفاء، التحكيم الاختياري والتحكيم الاجباري، ط5 ، منشأة المعارف، مصر

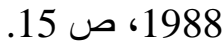
4- سيف الدين البلعاوي، التحكيم الدولي بين النظرية و التطبيق، الجزائر، 1989، ص

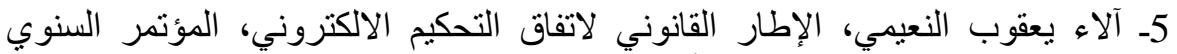

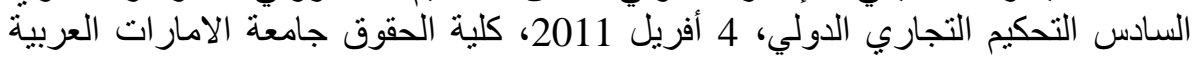

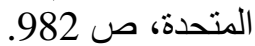

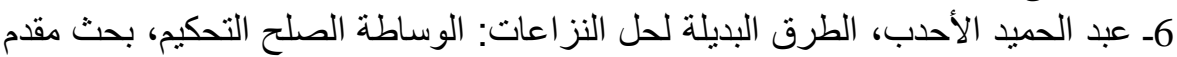

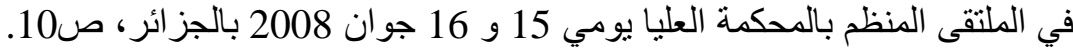

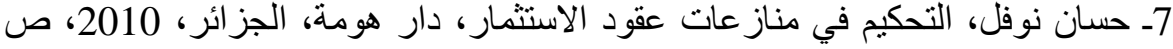

8- EDUARDO Silva Romero, discussion publier, dans la journée d'étude sur « le droit européen et l'arbitrage d'investissement » organisé le 08 décembre 2010, sous la direction de CATHERINE Kessedjian, à l'institut de droit comparé, université panthéon-assas ( Paris 02 ) ,édition Panthéos-Assas, Paris 2011, p 190.

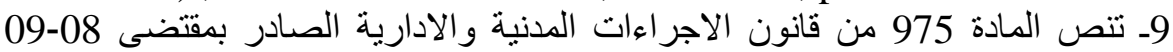
المؤرخ في 25 فيفري 2008 والمنشور بالجريدة الرسمية عدد 21 على الألى أنه " لايجوز 
للأشخاص المذكورين في المادة 800 أعلاه أن تجري تحكيما إلا في الحالات الواردة في

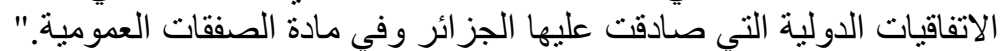

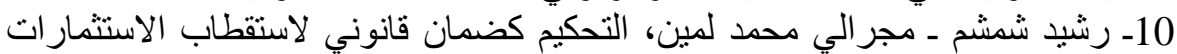

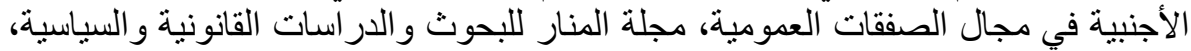

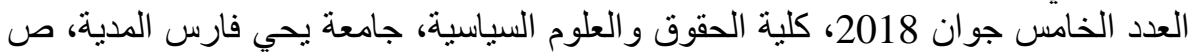

11- موساوي مليكة، التحكيم كطريق بديل لحل النزاع في مجال الصفقات العمومية، مجلة الحئة

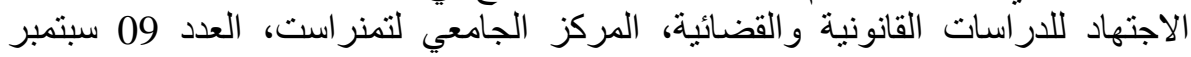
2015، ص صن الاد 228.

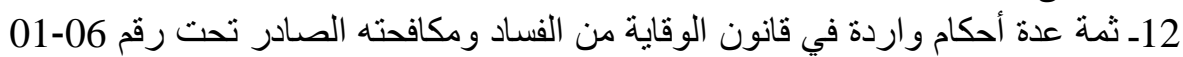

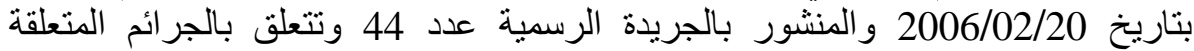

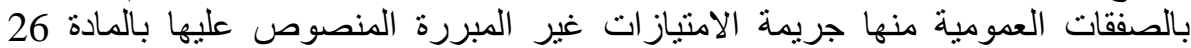

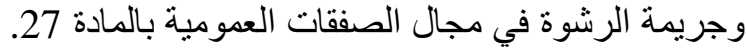
13- القانون الملغى هو فانون النون الاجراءات المدنية الصادر بوجب الأمر رقم 66-154

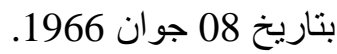
14- المرسوم التشريعي رقم 93 - 04 - 04 المؤرخ في 25 أفريل 1993 المعدل والمتمم

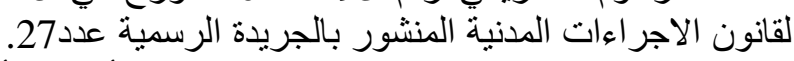

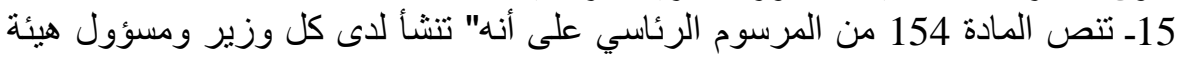

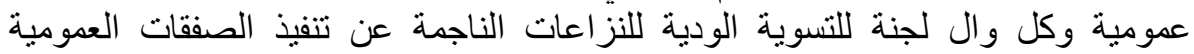

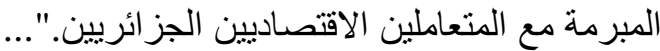

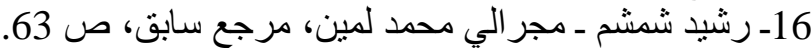
17- صديق سهام، التحكيم في منازعات تنفيذ التيذ الصفقات العمومية، المجلة المتوسطية

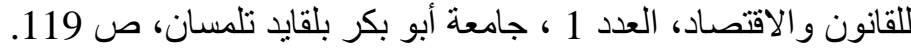

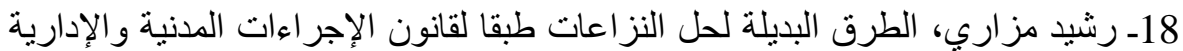

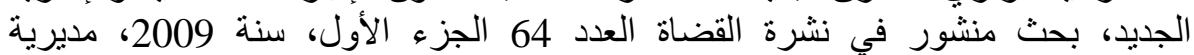

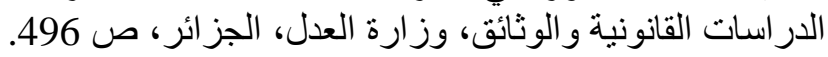

19-Philipe fauchard, Emmanuel Gaillard, Berthold, Traité de l'arbitrage commercial international, Paris, 1996, p 47 et Ss.

20ـ محمود السيد عمر التحيوي، التجاء الجهات الإدارية للتحكيم الاختياري في العقود

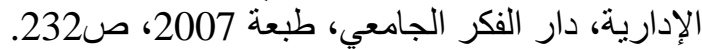

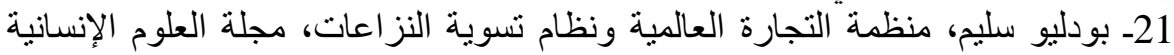

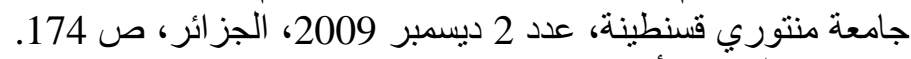

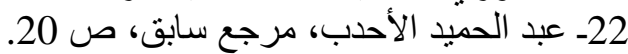

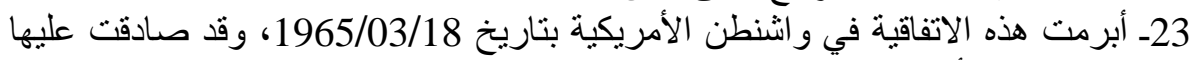

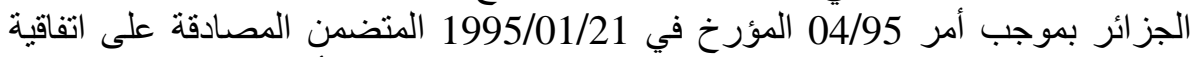

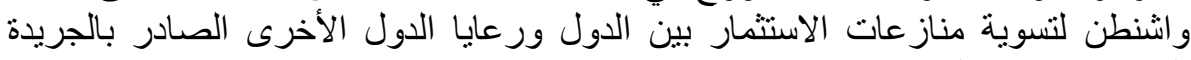

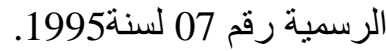
24- فايز نعيم رضوان، اتفاق التحكيم، بحث منشور في مجلة الأمن والقانون، السنة

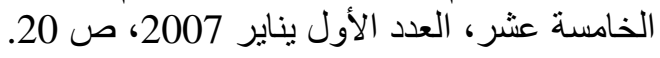

25-Mohand ISSAD, la nouvelle loi algérienne relative à l'arbitrage international, Revu de l'arbitrage, année 2008 n 3, p422.

26- لقد عرفه القانون الفرنسي سواء كان شرطا أو مشارطة و ذللك بالمرسوم رقم 812-

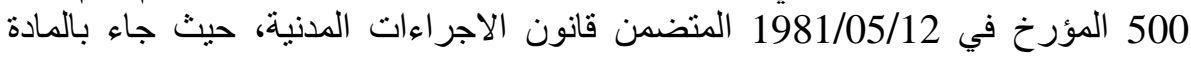




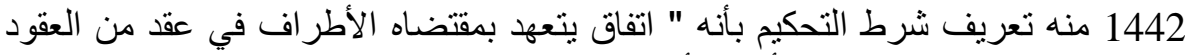

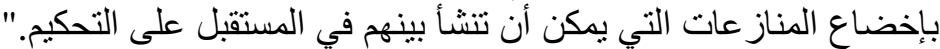

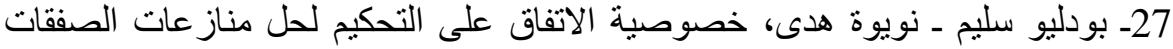

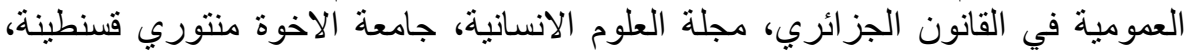

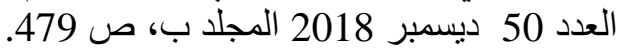

28- بنور أسماء، التحكيم في الصفقات العمومية الدولية، رسالة دكتور اهد، كلية الحقوق

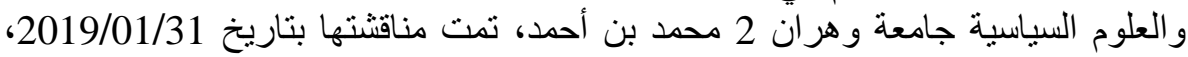

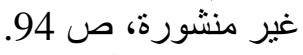

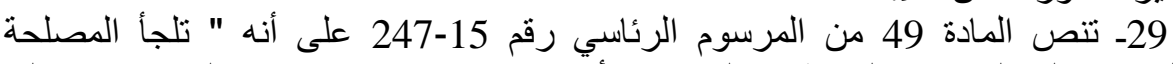

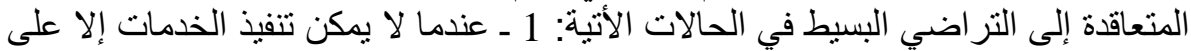

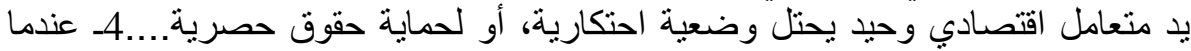
يتعلق الأمر بمشروع ذي أولوية و ذي أهمية وطنية يكتسي طابعا استعجالي."...

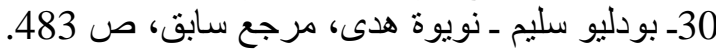

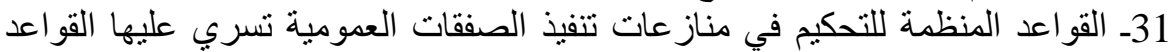

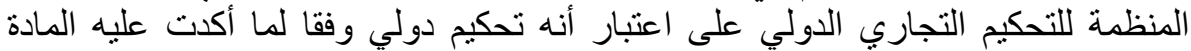

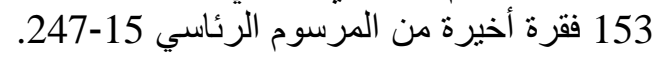

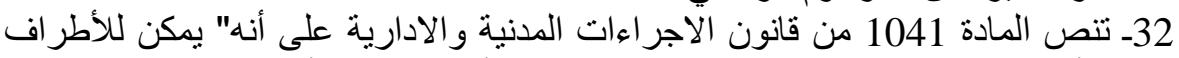

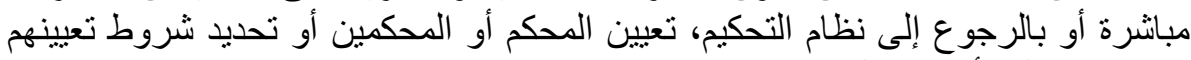
وشروط عزلهم أو استبدالهم."...

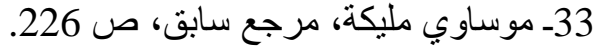

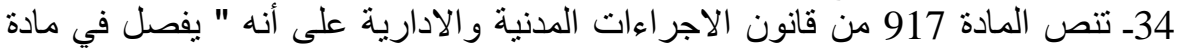

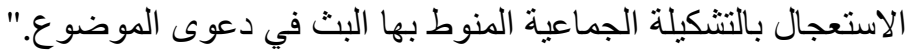

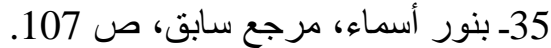

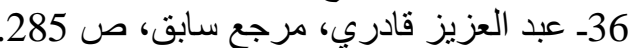

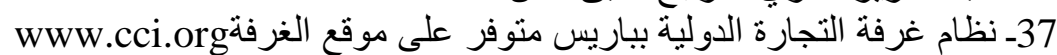

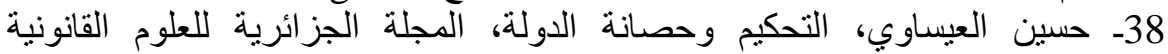
و الاقتصادية والسياسية، كلية الحقوق جامعة الجزائر 1 بن بوسف بل بن خدة، العدد 09 لسنة

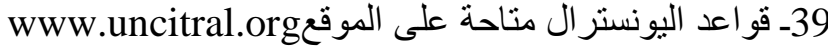

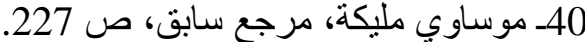
41- راجع تفصيل ذللك في رسالة الدكتور اه للباحثة بنور أسماء، مرجع سابق، ص 119 وما بعدها.

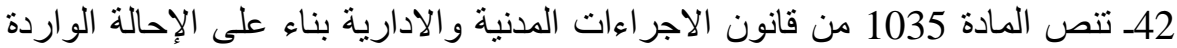

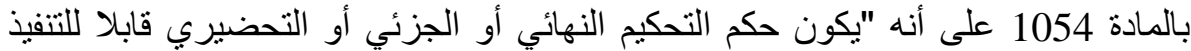

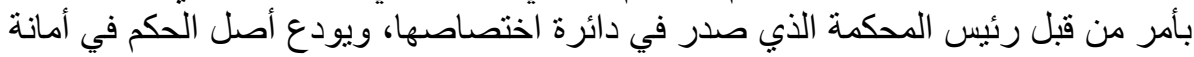

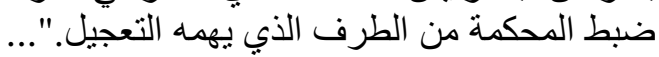

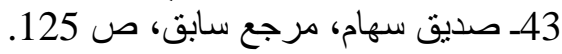
44- راجع تفصيل ذلك مداخلة بودليو سليم، الطعن بلفي بالبطلان في حكم التحكيم التجاري

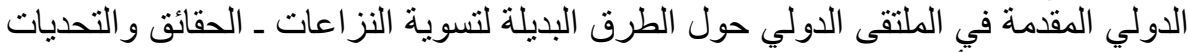
ـ يومي 26-27 أفريل 2016 بكلية الحقوق والعلوم السياسية، جامعة عبد الرحمان ميرة 